\title{
A Basal Forebrain Site Coordinates the Modulation of Endocrine and Behavioral Stress Responses via Divergent Neural Pathways
}

\author{
ㄴ) Shane B. Johnson, ${ }^{1}{ }^{\circ}$ Eric B. Emmons, ${ }^{1}{ }^{-}$Rachel M. Anderson, ${ }^{2}$ Ryan M. Glanz, ${ }^{2}$ Sara A. Romig-Martin, ${ }^{2}$ \\ Nandakumar S. Narayanan, ${ }^{1,3}$-Ryan T. LaLumiere, ${ }^{1,2}$ and $\odot$ Jason J. Radley ${ }^{1,2}$ \\ ${ }^{1}$ Interdisciplinary Neuroscience Program, ${ }^{2}$ Department of Psychological and Brain Sciences, and ${ }^{3}$ Department of Neurology, Carver College of Medicine, \\ University of Iowa, Iowa City, Iowa 52242
}

The bed nuclei of the stria terminalis (BST) are critically important for integrating stress-related signals between the limbic forebrain and hypothalamo-pituitary-adrenal (HPA) effector neurons in the paraventricular hypothalamus (PVH). Nevertheless, the circuitry underlying BST control over the stress axis and its role in depression-related behaviors has remained obscure. Utilizing optogenetic approaches in rats, we have identified a novel role for the anteroventral subdivision of BST in the coordinated inhibition of both HPA output and passive coping behaviors during acute inescapable (tail suspension, TS) stress. Follow-up experiments probed axonal pathways emanating from the anteroventral BST which accounted for separable endocrine and behavioral functions subserved by this cell group. The PVH and ventrolateral periaqueductal gray were recipients of GABAergic outputs from the anteroventral BST that were necessary to restrain stress-induced HPA activation and passive coping behavior, respectively, during TS and forced swim tests. In contrast to other BST subdivisions implicated in anxiety-like responses, these results direct attention to the anteroventral BST as a nodal point in a stressmodulatory network for coordinating neuroendocrine and behavioral coping responses, wherein impairment could account for core features of stress-related mood disorders.

Key words: bed nuclei of the stria terminalis; behavioral coping; corticosterone; HPA; paraventricular hypothalamus; periaqueductal gray area

Significance Statement

Dysregulation of the neural pathways modulating stress-adaptive behaviors is implicated in stress-related psychiatric illness. While aversive situations activate a network of limbic forebrain regions thought to mediate such changes, little is known about how this information is integrated to orchestrate complex stress responses. Here we identify novel roles for the anteroventral bed nuclei of the stria terminalis in inhibiting both stress hormone output and passive coping behavior via divergent projections to regions of the hypothalamus and midbrain. Inhibition of these projections produced features observed with rodent models of depression, namely stress hormone hypersecretion and increased passive coping behavior, suggesting that dysfunction in these networks may contribute to expression of pathological changes in stress-related disorders.

\section{Introduction}

Responses to stress involve a stereotyped activation of autonomic, behavioral, and neuroendocrine (i.e., hypothalamo-

Received March 30, 2016; revised June 30, 2016; accepted July 1, 2016.

Author contributions: S.B.J., N.S.N., R.T.L., and J.J.R. designed research; S.B.J., E.B.E., R.M.A., R.M.G., S.A.R.-M., and J.J.R. performed research; S.B.J., E.B.E., N.S.N., and J.J.R. analyzed data; S.B.J., N.S.N., R.T.L., and J.J.R. wrote the paper.

This work was supported by the National Institutes of Health (Grant MH-095972 to J.J.R., Grants DA034684 and MH-104384 to R.T.L., and Grant NS-089470 to N.S.N.) and the Brain \& Behavior Research Foundation (NARSAD Independent Investigator Grant to J.J.R.). We thank Dr. Karl Deisseroth for the material transfer agreement for the opsins.

The authors declare no competing financial interests. pituitary-adrenal, or HPA, axis) systems that play a vital role in adaptation. Conversely, dysregulation of neural systems that control stress-adaptive functions has been increasingly implicated in stress-related psychiatric illness (Sheline et al., 1996; Drevets et al., 1997; Videbech and Ravnkilde, 2004; MacQueen and Frodl, 2011; Price and Drevets, 2012). The bed nuclei of the stria terminalis (BST) and its subdivisions have been advanced as critically important nodal points in integrating stress-related signals

Correspondence should be addressed to Jason Radley, Department of Psychology, University of lowa, E11 Seashore Hall, lowa City, IA 52242. E-mail: Jason-radley@uiowa.edu.

DOI:10.1523/JNEUROSCI.1185-16.2016

Copyright $\odot 2016$ the authors $\quad 0270-6474 / 16 / 368687-13 \$ 15.00 / 0$ 
from the limbic forebrain to HPA effector neurons within the paraventricular nucleus of the hypothalamus (PVH). However, the existing body of evidence has led to conflicting interpretations of the precise role of BST in modulating stress-induced HPA output (Dunn, 1987; Casada and Dafny, 1991; Herman et al., 1994; Spencer et al., 2005; Choi et al., 2007; Choi et al., 2008; Radley et al., 2009; Radley and Sawchenko, 2011), highlighting the need to use more sophisticated approaches to clarify circuit mechanisms underlying stress adaptation. Similarly, there is a long-standing literature highlighting the role of BST in modulating approach-avoidance (e.g., fear, anxiety-like) behaviors (Walker et al., 2003; Davis et al., 2010; Jennings et al., 2013; Kim et al., 2013), although little attention has been given to its capacity to modulate behavioral coping during inescapable challenges. Moreover, the circuitry accounting for BST modulation of behavioral coping responses and its coordination with HPA activity during stress is unknown.

Here, we used optogenetic approaches to identify a novel role for the anteroventral subdivision of BST (avBST) in coordinating the modulation of HPA activation and behavioral coping during acute stress exposure. Photoexcitation and inhibition of avBST during the tail suspension (TS) test bidirectionally modulated (diminished and enhanced, respectively) central and hormonal indices of HPA activation. Photoinhibition of avBST cell bodies also increased immobility during TS, suggesting that avBST normally modulates behavioral coping behaviors in response to stress challenges. Follow-up experiments probed axonal pathways emanating from avBST. Notably, we found that GABAergic avBST inputs to $\mathrm{PVH}$ and the ventrolateral subdivision of the periaqueductal gray area (vlPAG) were necessary for restraining stress-induced HPA activation and passive coping behavior, respectively, during the TS and forced swim (FS) tests. These results direct attention to the avBST as a stress-modulatory nodal point of a circuit that coordinates neuroendocrine and behavioral adaptation, elucidating a novel site in a neural circuit wherein impairment could account for core features of stress-related mood disorders.

\section{Materials and Methods}

Animals and treatments. Adult male Sprague Dawley rats (225-250 g at the time of arrival, Charles River) acclimated to an American Association for Laboratory Animal Care-approved vivarium on a $12 \mathrm{~h}$ light/dark cycle (lights on at 0600) with food and water available ad libitum for at least $7 \mathrm{~d}$ before surgery. All procedures were approved by the University of Iowa Institutional Animal Care and Use Committee and were in accordance with the National Institutes of Health's Guide for the Care and Use of Laboratory Animals.

Surgeries. Rats were anesthetized with $4 \%$ isoflurane/oxygen, placed in a stereotaxic frame (Kopf Instruments), and maintained at 1.5-2\% isoflurane throughout surgery. Rats received preemptive analgesia $(2 \mathrm{mg} / \mathrm{kg}$ meloxicam) before an incision was made to expose the skull for craniotomy, virus injection, and fiber-optic implantation. Bilateral injections of adeno-associated virus (AAV, serotype $5 ; 0.5 \mu \mathrm{l} /$ side) were directed at avBST [anteroposterior (AP): $-0.10 \mathrm{~mm}$; mediolateral (ML): $1.20 \mathrm{~mm}$; dorsoventral (DV): $-7.45 \mathrm{~mm}$; all relative to bregma] via a 26 gauge Hamilton syringe. Rats were randomly assigned to groups receiving injections of AAV5 (University of North Carolina Vector Core) expressing enhanced yellow fluorescent protein (eYFP) alone (YFP control groups), ChannelRhodopsin2(E123A)-eYFP [ChR2(E123A)-eYFP; ChR2 groups), or enhanced archaerhodopsin 3.0-eYFP (eArch3.0-eYFP; Arch groups) under the control of a pan-neuronal promoter (human synapsin-1, hSyn). avBST microinjection placements were based on published stereotaxic coordinates from us and others and were laterally biased to avoid transduction of adjacent preoptic and parastrial regions (Radley et al., 2009, Radley and Sawchenko, 2011, 2015). After AAV injection, fiber optics [200 $\mu \mathrm{m}$ diameter, 0.37 numerical aperture (NA); Thorlabs) housed in steel ferrules (Plastics One) were lowered into place immediately dorsal to avBST somata (AP: $-0.10 \mathrm{~mm}$; ML: $2.70 \mathrm{~mm}$; DV: $-6.95 \mathrm{~mm} ; 10^{\circ}$ ), avBST terminal fields in PVH (AP: $-1.55 \mathrm{~mm}$; ML: 1.65 $\mathrm{mm}$; DV: $-7.00 \mathrm{~mm} ; 10^{\circ}$ ), or avBST terminal fields in vlPAG (AP: -7.45 $\mathrm{mm}$; ML: $1.75 \mathrm{~mm}$; DV: $\left.-5.50 \mathrm{~mm} ; 10^{\circ}\right)$ and secured with dental cement and surgical screws. After surgery, rats were given $4-6$ weeks for recovery and to allow adequate time for opsin expression throughout somata and axons. One week before stress experiments, animals were handled daily by the experimenter and habituated to the testing room.

Hormone assays. Two days before acute stress exposure, rats were implanted with indwelling jugular catheters based upon previous studies (Ericsson et al., 1994; Radley et al., 2006). Briefly, indwelling jugular catheters (polyethylene PE 50) containing sterile heparin-saline (50 $\mathrm{U} / \mathrm{ml}$ ) were implanted under isoflurane anesthesia. The sealed catheter was positioned with its internal SILASTIC (Dow-Corning) tip at the atrium and was exteriorized in the nape of the neck in the interscapular region. On the day of the experiment, at a time coinciding with the onset of the diurnal trough (0600) in circadian corticosterone levels (CORT), rats were brought to the procedure room, where jugular catheters were connected to sterile, $1 \mathrm{ml}$ syringes and flushed with heparinized saline. Dust caps were removed from the ferrules before the exposed fiber-optic interfaces were cleaned and connected to optical fibers $(200-\mu \mathrm{m}-$ diameter fiber, $0.37 \mathrm{NA}$; ThorLabs) contained in leashes. After at least 90 min of habituation, blood samples $(\sim 200 \mu \mathrm{l})$ were taken before ( $0 \mathrm{~min})$ stress exposure to estimate basal adrenocorticotropic hormone (ACTH) and CORT levels. Additional samples were collected immediately after TS (10 min) stress and at three subsequent time points $(30,60$, and 90 min after TS onset). After collection, each sample was immediately placed in a chilled conical vial containing $15 \mu \mathrm{l}$ of EDTA/ aprotinin, centrifuged for $20 \mathrm{~min}$, and fractionated for storage at $-80^{\circ} \mathrm{C}$. Plasma ACTH was measured using a two-site radioimmunometric assay (MP Biomedicals) with rabbit antisera raised against ACTH-BSA with ${ }^{125} \mathrm{I}-$ ACTH-BSA serving as a tracer. Intraassay and interassay coefficients of variation for ACTH radioimmunoassay were $3 \%$ and $7 \%$, respectively, with a sensitivity of $1.5 \mathrm{pg} / \mathrm{ml}$. Plasma corticosterone was measured without extraction using rabbit antisera raised against corticosterone-BSA with ${ }^{125} \mathrm{I}$-corticosterone-BSA serving as a tracer (MP Biomedicals), with intraassay and interassay coefficients of $5 \%$ and $10 \%$ and a sensitivity of $8 \mathrm{ng} / \mathrm{ml}$.

Stressors and behavioral observations. The TS test has been used widely in pharmacological and behavioral studies in mice (Steru et al., 1985), has been adapted for use in rats (Izumi et al., 1997; Zhang et al., 2008; Yang et al., 2014; Paumier et al., 2015), and induces stress responses robustly (Brown et al., 1984; Strekalova et al., 2004; Stone et al., 2011). Rats were suspended for $10 \mathrm{~min}$ by the tail such that their hindlimbs were elevated but forelimbs were allowed to touch the bottom of the cage (Chermat et al., 1986). Immobility tended to occur later in the stressor and was quantified as total time spent in a "passive coping" state wherein a total absence of limb and head movement were observed. Bouts of immobility were counted only if they occurred after the first $1 \mathrm{~min}$ of stress and lasted for at least $5 \mathrm{~s}$.

The FS test was used as an additional test of active versus passive coping behavioral responses to stress based on a previously described protocol (Porsolt et al., 1977; Detke and Lucki, 1996; Cryan et al., 2005). However, our test differed in that behavior was assessed over $10 \mathrm{~min}$ in stress-naive rats (i.e., without a pretest) to avoid a potential ceiling effect. Animals that had previously received AAV-Arch and fiber-optic implantation were placed in a $25-\mathrm{cm}$-diameter chamber filled to a depth of 30 $\mathrm{cm}$ with $25^{\circ} \mathrm{C}$ water and behavior was video recorded for $10 \mathrm{~min}$ concurrent with $561 \mathrm{~nm}$ illumination. Animals were then dried and returned to a clean cage warmed by a lamp and heating pad. Immobility was later scored as time spent in a passive (floating) as opposed to active coping state (swimming, climbing). To assess locomotor activity, rats were video recorded in a $38 \times 38 \mathrm{~cm}$ square open-field chamber for $10 \mathrm{~min}$ concurrent with $561 \mathrm{~nm}$ illumination. Later, velocity and distance traveled were quantified with EthoVision software (Noldus).

Illumination. Laser power was adjusted to deliver $10 \mathrm{~mW}$ at the tip of the implanted fiber optics, which, according to in vivo measurements, is 
sufficient to activate opsins within a sphere (radius $\approx 0.46 \mathrm{~mm}$ ) below the termination of the fiber optic (Yizhar et al., 2011; Huff et al., 2013). During experiments, ChR2 animals received $5 \mathrm{~ms}$ pulses of $473 \mathrm{~nm}$ light (Opto Engine) at $20 \mathrm{~Hz}$ (Master-9 pulse generator), Arch animals received constant illumination with $561 \mathrm{~nm}$ light (Laser Century), and YFP controls received the same illumination as their respective ChR2 and Arch counterparts. For all experiments, illumination began with TS and proceeded concurrently with the $10 \mathrm{~min}$ duration of stress exposure, except for one experiment that involved a $30 \mathrm{~min}$ stimulation interval (e.g., see Fig. 7). In the latter instance, our goal was to ascertain whether stress-induced HPA activation could be more strongly modulated by extending the illumination period into the poststress recovery period.

Optrode recordings. In a separate experiment, rats that had previously ( $>4$ weeks prior) received stereotaxic injections into avBST of both AAV5-hSyn-ChR2(E123A)-eYFP and AAV5-hSyn-eArch3.0-eYFP or AAV5-hSyn-eYFP alone were anesthetized with $4 \%$ isoflurane. Next, a surgical level of anesthesia was attained with intraperitoneal injection of ketamine $(100 \mathrm{mg} / \mathrm{kg})$ and xylazine $(10 \mathrm{mg} / \mathrm{kg})$ and maintained with supplementary injections of ketamine $(30 \mathrm{mg} / \mathrm{kg})$ as necessary. The scalp was then retracted and the skull leveled between bregma and lambda before a craniotomy was made stereotaxically above the avBST of the left hemisphere. Another small hole was drilled for insertion of the ground wire and two skull screws were implanted to secure the ground wire.

Recordings were collected using a combined microwire array and optical fiber, or "optrode" (MicroProbes for Life Science). The optrode was positioned above avBST ( $\mathrm{AP}-0.10, \mathrm{ML}-1.20 \mathrm{~mm}$ relative to bregma) and slowly lowered $(0.1 \mathrm{~mm} / \mathrm{min})$ into an initial location in the dorsalmost aspect of the structure (DV $-7.2 \mathrm{~mm}$, relative to dura). Single neurons were identified online using an oscilloscope and audio monitor and neuronal recordings were made using a multielectrode recording system (Plexon). After a pause to ensure that the recording was stable, the following optogenetic protocol was initiated to determine whether avBST neurons were modulated by illumination: 0:00-15:00 $\mathrm{min}$, no laser on; 15:00-30:00 min, $473 \mathrm{~nm}$ laser pulsed at $20 \mathrm{~Hz}$ with $10 \%$ duty cycle; 30:00 - 45:00 min, only $561 \mathrm{~nm}$ laser on. After the initial recording, the optrode was advanced ventrally in $\sim 0.3 \mathrm{~mm}$ increments for a total of 4 recordings spanning $\sim 1 \mathrm{~mm}$. After the recording session, the hardware was removed and animals were prepared for histology (see "Histology and tissue processing" section).

The Plexon Off-Line Sorter program was used to analyze the signals offline and remove artifacts. Spike activity was analyzed for all cells that fired at rates $>0.1 \mathrm{~Hz}$. Principal component analysis (PCA) and waveform shape were used for spike sorting. Single units were identified as having the following: (1) consistent waveform shape, (2) separable clusters in PCA space, (3) average amplitude estimated at least three times larger than background activity, and (4) a consistent refractory period of at least $2 \mathrm{~ms}$ in interspike interval histograms. Analysis of neuronal activity and quantitative analysis of basic firing properties were performed using NeuroExplorer (Nex Technologies) and with custom routines for MATLAB (The MathWorks).

Histology and tissue processing. Rats were anesthetized with pentobarbital $(100 \mathrm{mg} / \mathrm{kg}$, i.p.) and perfused at a rate of $55 \mathrm{ml} / \mathrm{min}$ through the ascending aorta with $100 \mathrm{ml}$ of $0.9 \% \mathrm{NaCl}$, followed by $900 \mathrm{ml}$ of ice-cold $4 \%$ paraformaldehyde (PFA). Brains were then harvested, postfixed in $4 \% \mathrm{PFA}$ at $4^{\circ} \mathrm{C}$ for $4 \mathrm{~h}$, and then cryoprotected in a solution containing $20 \%$ sucrose/KPBS overnight. The following day, brains were frozen on dry ice and sections were cut in the coronal plane in a one-in-five series at $30 \mu \mathrm{m}$ on a sliding microtome (Leica) and collected in a cryopreservative solution before storage at $-20^{\circ} \mathrm{C}$.

Histochemistry. Fos protein was immunolocalized in free-floating sections using a previously described avidin-biotin peroxidase method (Sawchenko et al., 1990; Radley et al., 2008) and primary antiserum raised against residues $4-17$ of rat Fos protein synthesized by J. Rivier (The Salk Institute). Endogenous peroxidase activity was neutralized by 10 min of pretreatment with $0.3 \% \mathrm{H}_{2} \mathrm{O}_{2}$ before incubating at $4^{\circ} \mathrm{C}$ for $48 \mathrm{~h}$ in primary antiserum ( $1: 25 \mathrm{k}$ in PBS $+0.3 \%$ Triton X-100 + 3\% normal goat serum). Fos primary antiserum was reacted with Vectastain Elite (Vector Laboratories) reagents and the reaction product was developed using a nickel-enhanced glucose oxidase method (Sawchenko et al.,
1990). GAD-65 was immunolocalized with a mouse monoclonal antibody from the University of Iowa Developmental Studies Hybridoma Bank (1:100; GAD-6 deposited by David I. Gottlieb) and visualized with goat anti-mouse Alexa Fluor 568 (1:500; Thermo Fisher). CRF was immunolocalized with an anti-rat CRF-68 antibody raised in rabbit (Sawchenko Laboratory, The Salk Institute) and then amplified and visualized with biotinylated goat anti-rabbit IgG and streptavidin conjugated Alexa Fluor 633 (Thermo Fisher). YFP-expressing neurons and terminals were visualized either with native fluorescence or immunofluorescence after incubation in rabbit anti-GFP (1:25k; Thermo Fisher) and goat antirabbit Alexa Fluor 488 (1:500; Thermo Fisher).

Techniques for probe synthesis, hybridization, and autoradiographic localization of mRNA signal were adapted from Simmons et al. (1989). In situ hybridization was performed using ${ }^{35} \mathrm{~S}$-labeled sense (control) and antisense cRNA probes labeled to similar specific activities using a fulllength probe for mRNA encoding the $67 \mathrm{kDa}$ isoform of glutamic acid decarboxylase (GAD67, Dr. A. Tobin, University of California, Los Angeles; Erlander et al., 1991). Probes for the vesicular glutamate transporter, types 1 and 2 (VGLUT1 and VGLUT2) were derived from mouse cDNAs (Open Biosystems) bearing a high degree of homology to rat (VGLUT1: 96\% homology to nucleotides 65-437 of rat VGLUT1, GenBank accession number BE950784; Dr. H. Chin, National Institute of Mental Health-National Institutes of Health, Bethesda, MD; VGLUT2: $94 \%$ homology to nucleotides 545-1070 of rat VGLUT2, accession number CB247147; Dr. R. Strausberg, National Institutes of Health, Bethesda, MD). Hybridization using antisense probes for VGLUT1 and VGLUT2 yielded labeling that conformed with the reported distributions in rat brain (Ziegler et al., 2012) and sense probes for each did not provide evidence of specific labeling. Isotopic hybridization histochemical localization GAD67 or VGLUT mRNA, was performed using a previously described protocol (Radley et al., 2009; Radley et al., 2013).

Quantitative histological analyses. High-resolution ( $100 \times$ objective, 1.4 NA) $z$-stacks were collected with a Leica SP5 confocal microscope (pinhole set to 1 airy unit) to estimate the percentage colocalization of GABAergic and glutamatergic synaptic markers with YFP puncta in PVH and vlPAG. Briefly, YFP-fluorescent puncta were identified visually and marked within single sections using ImageJ. Markers representing the locations of YFP puncta were then overlaid on corresponding GAD65 or vGlut fluorescent optical sections and colocalizations were noted. Colocalization estimates reported below represent mean values $[n=3$ animals, 3 optical sections/animal/brain region (PVH, vlPAG)].

Stereological methods were used to quantify the number of Fosimmunoreactive neurons using a computer-assisted morphometry system (MBF Biosciences). For each analysis, boundaries defining the regions of interest were drawn at $10 \times$ using an adjacent series of Nisslstained sections. Analyses of Fos-immunoreactive cells were performed on every fifth section, avoiding cells in the outermost plane of focus. To probe for possible treatment effects of stereotaxic and viral manipulations on regional anatomical volume, 3D estimates from cross-sectional area measurements were obtained using the Cavalieri method, but no effects were observed.

Statistics. Grouped data from the immunohistochemical and behavioral experiments were analyzed using a factorial ANOVA, with optogenetic treatment and stress status serving as factors, followed by post hoc pairwise comparisons using Fisher's least significant difference test. Group data from the hormone assays were compared with a mixeddesign ANOVA with one within-group variable (time) and one betweengroup variable, followed by individual pairwise comparisons as above. Data are expressed as the mean \pm SEM.

\section{Results}

\section{Photoinhibition of avBST exaggerates stress responses}

In an initial series of experiments, we addressed the functional role of avBST in shaping endocrine and behavioral coping responses by activating inhibitory opsins within neuronal somata concurrent with stress exposure. A 4-week recovery period after microinjection of either AAV-Arch or AAV-YFP into avBST was sufficient to produce robust expression of YFP within neuronal 

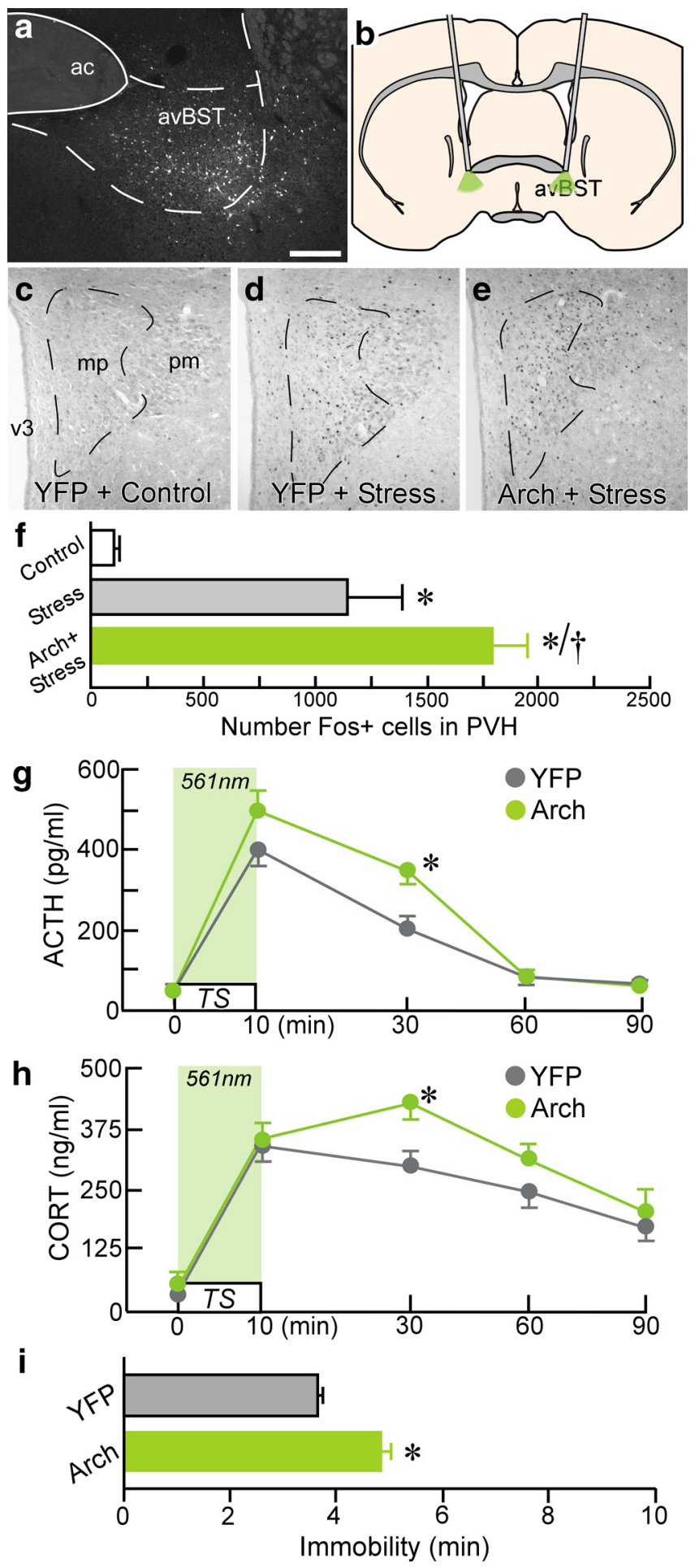

Figure 1. Endocrine and behavioral consequences of avBST somata photoinhibition. $\boldsymbol{a}-\boldsymbol{e}$, Dark-field image (left) of a coronal section showing YFP-fluorescent neuron soma after AAV microinjection into avBST, with a schematic coronal section $(\boldsymbol{b})$ illustrating fiber optic placement for the bilateral photoinhibition of neuronal somata therein. Example photomicrographs showing Fos immunoperoxidase labeling in PVH from unstressed YFP control (c), as well as YFP $(\boldsymbol{d})$ and Arch (e) rats subjected to TS, illustrating a marked increase in Fos immunoreactivity after avBST somata photoinhibition. Scale bar, $200 \mu \mathrm{m}(\boldsymbol{a}, \boldsymbol{c}-\boldsymbol{e})$. $\boldsymbol{f}$, Quantification of Fosimmunoreactive nuclei reveals a significant induction as a result of stress exposure $\left({ }^{*} p<0.05\right)$ and further enhancement associated with photoinhibition of avBST neuron axons ( $t p<0.05$ ). $n=3$ YFP + control, $n=7$ YFP + stress, $n=6$ Arch + stress. $g$, Analysis of ACTH levels before and after $10 \mathrm{~min}$ TS coincident with $561 \mathrm{~nm}$ illumination (light green shaded area) of avBST somata. $\boldsymbol{h}$, Plasma levels of CORT were significantly elevated in Arch animals 30 min after the onset of stress versus YFP controls $\left({ }^{*} p<0.05\right)$. Arch stimulation resulted in a prolonged somata (Fig. 1a). Rats bearing fiber-optic implantations directly above avBST for photoinhibition of neuronal somata were subjected to $10 \mathrm{~min}$ of TS with concurrent bilateral $561 \mathrm{~nm}$ laser illumination along with repeated blood sampling performed at time points before and after stress (Fig. $1 b$ ). One-way ANOVA revealed a main effect of treatment on Fos induction in the parvicellular subdivision of the PVH $\left(F_{(2,13)}=12.0 ; p<0.05\right)$. Each group exposed to TS showed increases in the number of Fosimmunoreactive cells in PVH compared with the unstressed control group ( $p<0.05$ for each) and rats receiving photoinhibition of Arch in avBST somata exhibited a further enhancement of Fos relative to YFP controls receiving the same light stimulation (by $56 \%, p<0.05$; Fig. $1 c-f$ ). Ancillary experiments comparing Fos induction in $\mathrm{PVH}$ in rats lacking viral injections with rats bearing AAV-YFP injections in avBST failed to reveal any effect of transgene expression on this index of stress-induced $\mathrm{PVH}$ activation (data not shown).

Comparison of HPA secretory responses were performed as a function of photoinhibition of avBST cell bodies concurrent with 10 min of TS stress exposure. Mixed-design ANOVA, with time as a within-subjects factor and between-subjects as AAV-defined groups, was performed on ACTH radioimmunoassay data and revealed main effects of treatment $\left(F_{(1,11)}=5.9 ; p<0.05\right)$, time $\left(F_{(4,44)}=74.8 ; p<0.05\right)$, and a significant interaction between these variables $\left(F_{(4,44)}=3.8 ; p<0.05\right)$. Within-group measures demonstrated significant increases in peak ACTH levels $(10 \mathrm{~min}$, $p<0.05$ ) that returned to baseline by $60 \mathrm{~min}$ in all rats subjected to TS, whereas ACTH levels were augmented in Arch rats relative to YFP counterparts (at $30 \mathrm{~min}, p<0.05$; Fig. $1 g$ ). Mixed-design ANOVA for CORT radioimmunoassay data mirrored the trends of ACTH release, although only main effects for time $\left(F_{(4,44)}=\right.$ 5.4; $p<0.05)$ were noted. Nevertheless, Arch rats displayed significantly enhanced levels of plasma CORT at 30 min compared with the YFP control group $(p<0.05$; Fig. $1 h)$. Examination of integrated $\mathrm{ACTH}$ and CORT responses over time (i.e., the area under the curve measurement) also revealed a significant increase in Arch animals compared with the YFP group $(p<0.05)$ for ACTH but not for CORT $(p=0.2)$.

Immobility behavior was also quantified during TS in the same groups of rats submitted to repeated blood sampling because this provides a measure of the extent to which rats use active versus passive coping strategies during this inescapable stressor. Moreover, assessment of immobility in this test has also been widely used as a measure of behavioral despair, largely based upon its capacity to be modulated by antidepressants (Steru et al., 1985; Chermat et al., 1986; Paumier et al., 2015). Rats that received photoinhibition of avBST throughout $10 \mathrm{~min}$ of the TS procedure spent significantly more time in an immobile state than YFP controls receiving the same illumination (by $32 \%, p<$ 0.05 ; Fig. $1 i$ ), implicating avBST in the modulation of both behavioral coping and in constraining HPA activation during stress exposure.

We then confirmed photoinhibition of spiking in putative Arch-expressing avBST neurons with the same constant $561 \mathrm{~nm}$ illumination paradigm used in the preceding stress experiments. A combined microelectrode array and optical cannula (i.e., optrode) was lowered into the avBST of rats $(n=2)$ that had pre-

elevation of plasma titers of ACTH and CORT (at $30 \mathrm{~min}$ ) after stress onset compared with YFP control animals $\left({ }^{*} p<0.05\right)$. $\boldsymbol{i}$, Photoinhibition of avBST somata was associated with a significant increase in immobility behavior during TS. $n=6$ YFP, $n=6 \operatorname{Arch}(\boldsymbol{f}-\boldsymbol{i})$. 

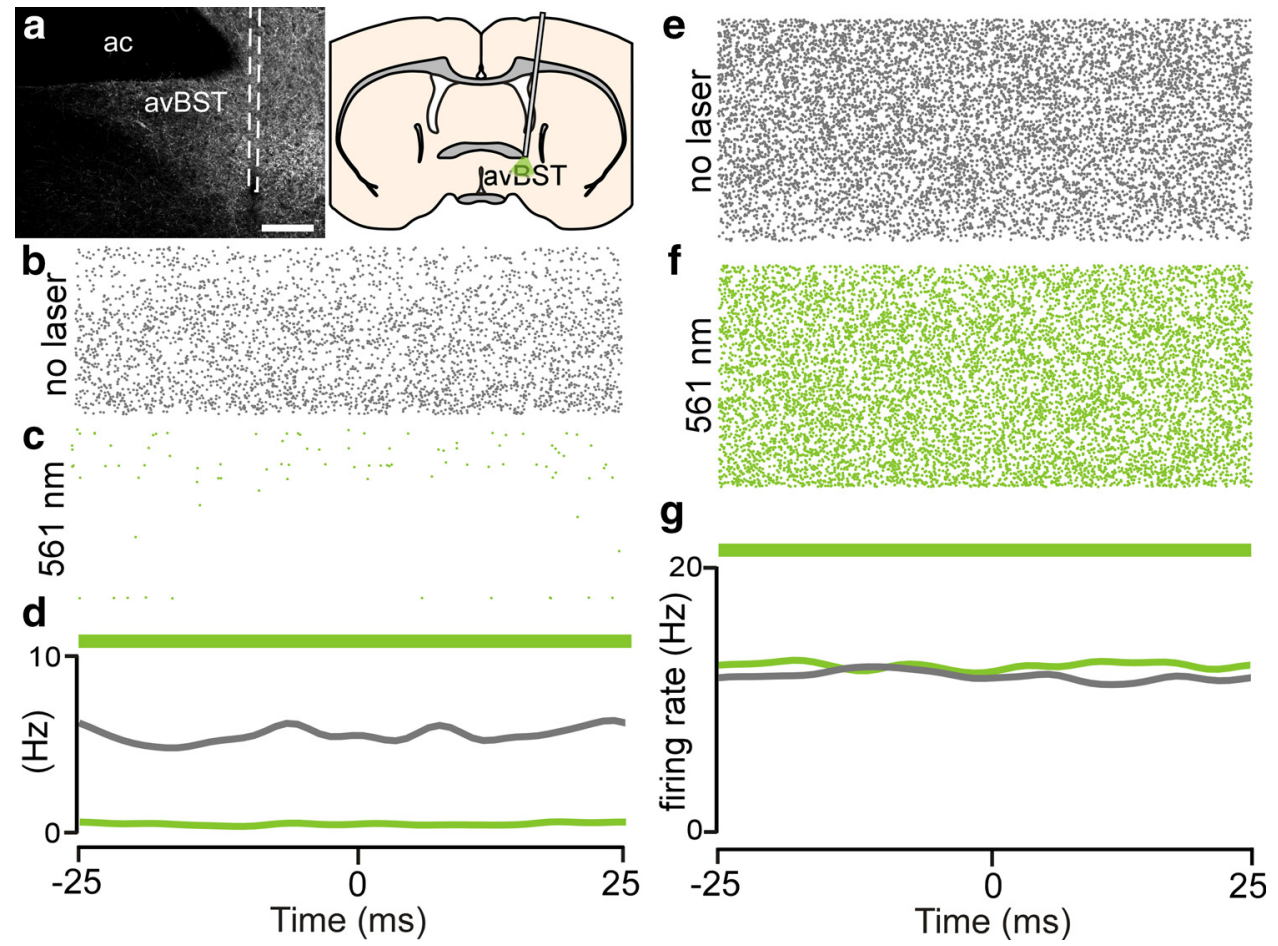

Figure 2. Neurophysiological confirmation of Arch-mediated photoinhibition. $\boldsymbol{a}$, Epifluorescent image (left) displaying the microelectrode path (dashed line) along which neurophysiological activity was recorded ventral to the anterior commissure (ac) to confirm suppression of neuronal activity with $561 \mathrm{~nm}$ light, with schematic diagram (right) illustrating optrode placement during the recording session. Scale bar, $200 \mu \mathrm{m} . \boldsymbol{b}$ - $\boldsymbol{d}$, Example of activity over $15 \mathrm{~min}$ recording sessions in the absence (gray raster plot; $\boldsymbol{b}$ ) and presence (green raster plot; $\boldsymbol{c}$ ) of constant $561 \mathrm{~nm}$ illumination in a putative Arch-expressing avBST unit, with summary histogram (d) illustrating suppression of neuronal firing (gray line, no laser session; green line, $561 \mathrm{~nm}$ laser session). $\boldsymbol{e}-\boldsymbol{g}$, In a YFP-microinjected animal, neuronal firing was unchanged between the unilluminated $(\boldsymbol{e})$ and $561 \mathrm{~nm}$ illuminated periods $(\boldsymbol{f})$, which are summarized in a histogram $(\boldsymbol{g})$. Green bars indicate continuous laser illumination over $50 \mathrm{~ms}$ blocks.

viously ( $>4$ weeks prior) received microinjections of AAV-ChR2 and AAV-Arch in the same brain structure (Fig. 2a). Recordings that were made before and concurrent with $561 \mathrm{~nm}$ illumination showed substantial suppression of firing rate in Arch-expressing (Fig. $2 b-d$ ), but not YFP-expressing, avBST neuronal somata (Fig. 2e-g).

\section{Photoexcitation of avBST cell bodies}

avBST receives extensive excitatory input from upstream prefrontal cortical and hippocampal regions that are known to inhibit stress-induced HPA activation (Herman et al., 1995; Radley et al., 2009; Hill et al., 2011; Radley and Sawchenko, 2011), thus positioning avBST as a gateway for limbic forebrain modulation of adaptive responses to stress. Therefore, we investigated whether optogenetically stimulating avBST somata abrogates endocrine and behavioral responses to acute stress. Rats received bilateral microinjections of AAVs expressing ChR2 or YFP into, and fiber optic implantation above, avBST, followed by a 4-week recovery, and were then fitted with indwelling jugular catheters $2 \mathrm{~d}$ before the blood collection experiment.

First, we investigated whether photoexcitation of avBST during stress promotes Fos induction in avBST and, in turn, reduces functional activation within PVH. Because the projections from avBST to PVH are predominantly ipsilateral (Dong et al., 2001), we hypothesized that unilateral ChR2 activation in avBST would be associated with increased Fos expression in avBST somata relative to the unilluminated side and with decreased Fos expression within its projection fields in the ipsilateral PVH (Fig. 3a-d). Consistent with this, stress induced Fos expression in avBST cell groups compared with unstressed controls $\left(F_{(1,5)}=17.2\right.$; $p<$ $0.05)$ and unilateral avBST photostimulation increased Fos ex- pression ipsilaterally in both control and stress groups compared with nonstimulated counterparts $\left(F_{(1,5)}=15.5 ; p<0.05\right.$; Fig. 3e). Repeated-measures ANOVA based on counts of Fosimmunoreactive nuclei revealed significant increases in PVH after stress $\left(F_{(1,5)}=9.3 ; p<0.05\right)$. Nevertheless, ChR2-avBST stimulation produced decrements in stress-induced activation within the ipsilateral $\operatorname{PVH}\left(F_{(1,5)}=8.1 ; p<0.05\right)$, along with a corresponding significant interaction as a function of stress treatment and laterality $\left(F_{(1,5)}=7.6 ; p<0.05\right.$; Fig. 3f).

In a separate experiment, we examined HPA secretory responses to $10 \mathrm{~min}$ of TS in rats receiving concurrent bilateral 473 nm laser illumination of avBST somata ( $20 \mathrm{~Hz}$ light pulses, $5 \mathrm{~ms}$ pulse width). Mixed-design ANOVA was performed on ACTH radioimmunoassay data and revealed main effects of treatment $\left(F_{(1,12)}=8.5 ; p<0.05\right)$ and time $\left(F_{(4,48)}=65.2 ; p<0.05\right.$; Fig. $4 a)$. Analysis of CORT radioimmunoassay data revealed main effects of treatment $\left(F_{(1,12)}=4.5 ; p=0.05\right)$ and time $\left(F_{(4,48)}=\right.$ $55.2 ; p<0.05)$. Between-group comparisons at individual time points revealed that CORT levels were significantly decreased in ChR2 animals compared with YFP control animals at 10 and 90 $\min (p<0.05$ for each; Fig. $4 b)$. Furthermore, area under the curve analyses for stress hormonal activity patterns revealed decreased integrated ACTH responses in ChR2 rats compared with the YFP control group $(p<0.05)$. However, analysis of immobility behavior during 10 min of TS in ChR2-avBST photostimulated rats failed to reveal any significant differences compared with controls ( $p=0.4$; Fig. $4 c)$.

Ancillary experiments confirmed that photoexcitation of putative ChR2-expressing avBST neurons increased neuronal activity. Optrode recordings were taken from the avBST $(n=2)$ of animals that had previously received microinjections of AAV- 

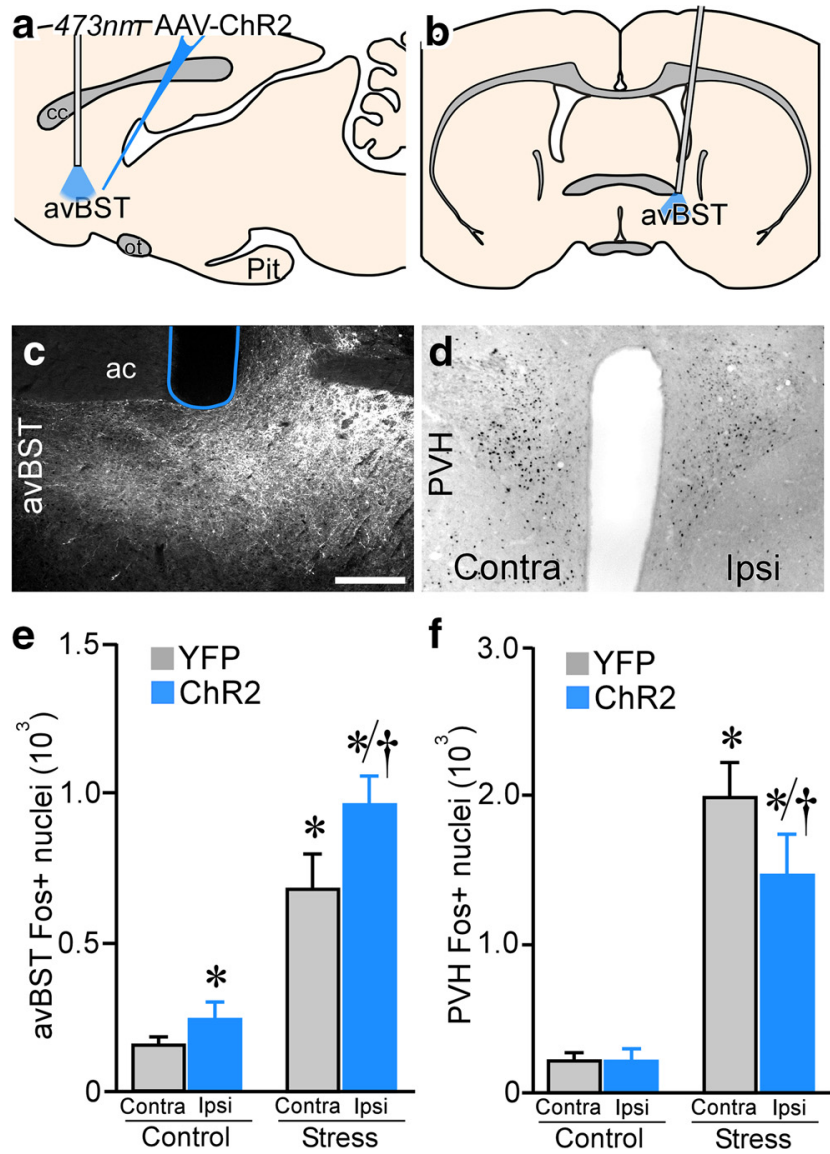

Figure 3. Changes in Fos induction after unilateral avBST somata photoexcitation. $\boldsymbol{a}$, Sagittal diagram depicting bilateral AAV-ChR2 microinjection into, and fiber-optic placement above, avBST for unilateral avBST somata photoexcitation. $\boldsymbol{b}$, Coronal view). c, Dark-field image illustrating fiber-optic (blue outline) placement ventral to the anterior commissure (ac) and immediately dorsal to ChR2:YFP-expressing neurons in avBST. $\boldsymbol{d}$, Brightfield photomicrograph showing Fos immunoperoxidase staining in PVH contralateral and ipsilateral (contra and ipsi, respectively) to the photoexcited side of avBST after TS. Scale bar, $200 \mu \mathrm{m}(\boldsymbol{c}, \boldsymbol{d}) . \boldsymbol{e}$, Counts of Fos-positive nuclei revealed significant increases within the photoexcited side of avBST in both stressed and unstressed control animals compared with the contralateral side of unstressed animals $\left({ }^{*} p<0.05\right)$. In stressed animals, illumination was associated with further increases in Fos induction relative to the contralateral side $(t p<0.05)$. $f$, Whereas stressed animals displayed overall increases in Fos induction in PVH relative to controls $\left({ }^{*} p<0.05\right)$, the side of PVH ipsilateral to avBST photoexcitation showed abrogated responses relative to the contralateral side $(\dagger p<0.05) . n=3$ control, $n=5$ stress $(\boldsymbol{e}, \boldsymbol{f})$.

ChR2 and AAV-Arch in the avBST. Recording sessions lasted for 15 min with identical illumination parameters to those used in the preceding stress experiments $(20 \mathrm{~Hz}, 5 \mathrm{~ms}$ pulse width, 473 $\mathrm{nm})$. Neurons in avBST displayed increased phasic firing rates in response to $473 \mathrm{~nm}$ light (Fig. $5 a-c$ ); however, we failed to observe nonspecific effects of this illumination paradigm in optrode data collected in an AAV-eYFP animal (Fig. 5d-f). These data, coupled with the functional experiments, provide confirmation of the efficacy of ChR2-mediated photoexcitation in this structure and also suggest that avBST activity produces reliable downstream reductions in $\mathrm{PVH}$ activation.

\section{Photoinhibition of avBST terminal fields in PVH}

Although the foregoing experiments highlight the capacity of avBST to modulate stress-induced HPA activation bidirectionally, we sought to determine the circuit basis for this phenomenon by manipulating the axonal pathway from avBST to PVH. That avBST inhibition and excitation enhances and dampens
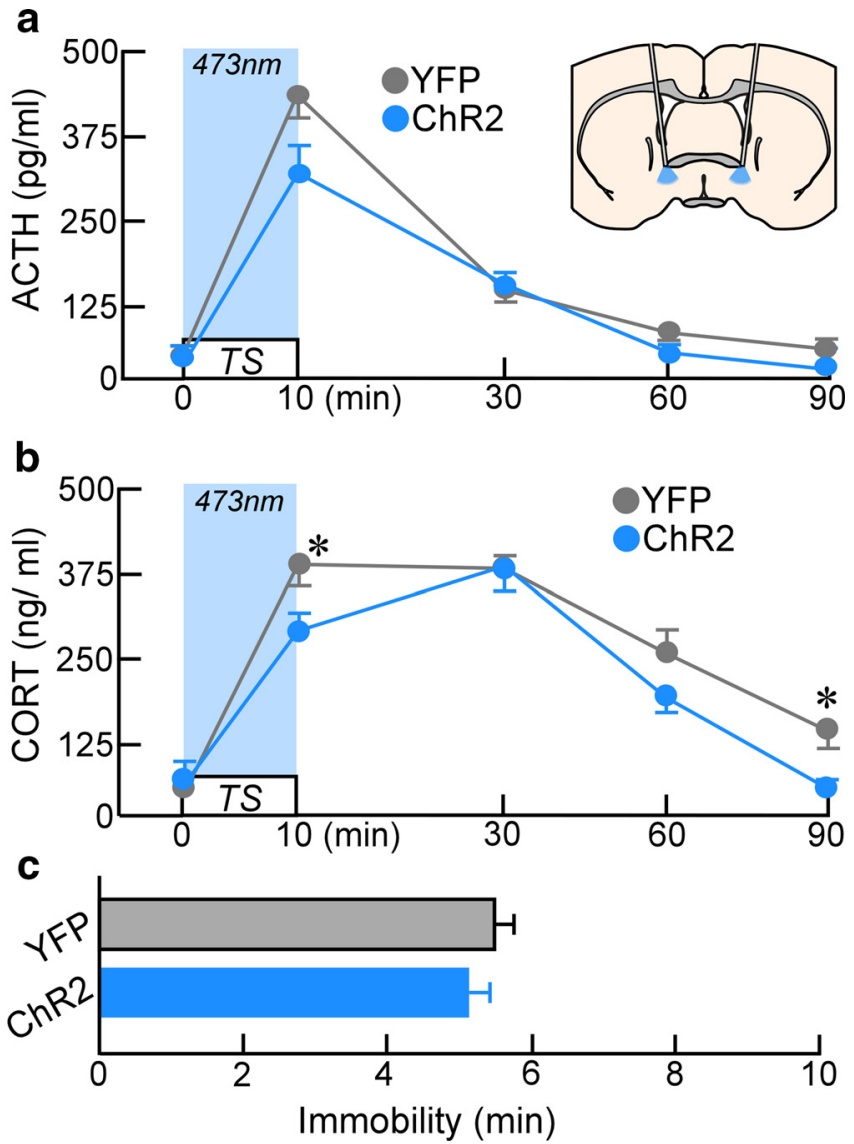

Figure 4. Endocrine and behavioral consequences of bilateral avBST photoexcitation Analysis of ACTH levels before $(\boldsymbol{a})$ and after $10 \mathrm{~min}$ of TS concurrent with bilateral photoexcitation (light blue shaded area) of avBST somata failed to reveal any significant differences for any individual time point, whereas CORT levels $(\boldsymbol{b})$ were significantly reduced in ChR2 animals immediately after TS (at $10 \mathrm{~min}$ ) and at 90 min after its onset ( ${ }^{*} p<0.05$ ). $\boldsymbol{i}$, Immobility behavior during TS did not differ between ChR2 and YFP groups ( $p=0.4$ ). $n=7$ per group $(\boldsymbol{a}-\boldsymbol{c})$.

stress-induced HPA activation, respectively, suggests that this region exerts inhibitory control over the stress axis. Nevertheless, whereas previous work suggests that the avBST-to-PVH pathway is GABAergic, the complex cytoarchitecture and neuronal phenotypes within this brain region have hindered attempts to resolve this issue using conventional techniques (Dunn, 1987; Cullinan et al., 1993; Cecchi et al., 2002; Choi et al., 2007; Radley et al., 2009; Radley and Sawchenko, 2011).

To characterize avBST cell and projection phenotypes, we first evaluated the extent of GAD and VGLUT (i.e., a glutamatergicspecific neuronal marker) mRNA expression. Hybridization histochemistry confirmed that the vast majority of neurons in this BST subdivision are GABAergic, with a scant proportion of glutamatergic cells (Fig. 6a,b). Immunohistochemical analysis showed that YFP-fluorescent terminals formed a dense plexus throughout medial parvicellular PVH in rats bearing AAV injections within avBST. Confocal laser-scanning microscopic analysis in PVH revealed extensive YFP-fluorescent puncta, most of which $(87 \%)$ colocalized with the GABA synthetic enzyme GAD-65 (Fig. $6 c, d$ ). Moreover, many colabeled YFP + GAD puncta resided in close apposition to CRF-immunoreactive secretory neurons (Fig. $6 e, f$ ). Furthermore, immunohistochemical staining for vGlut2 revealed no colocalization with YFP-positive terminals originating in avBST (data not shown). 

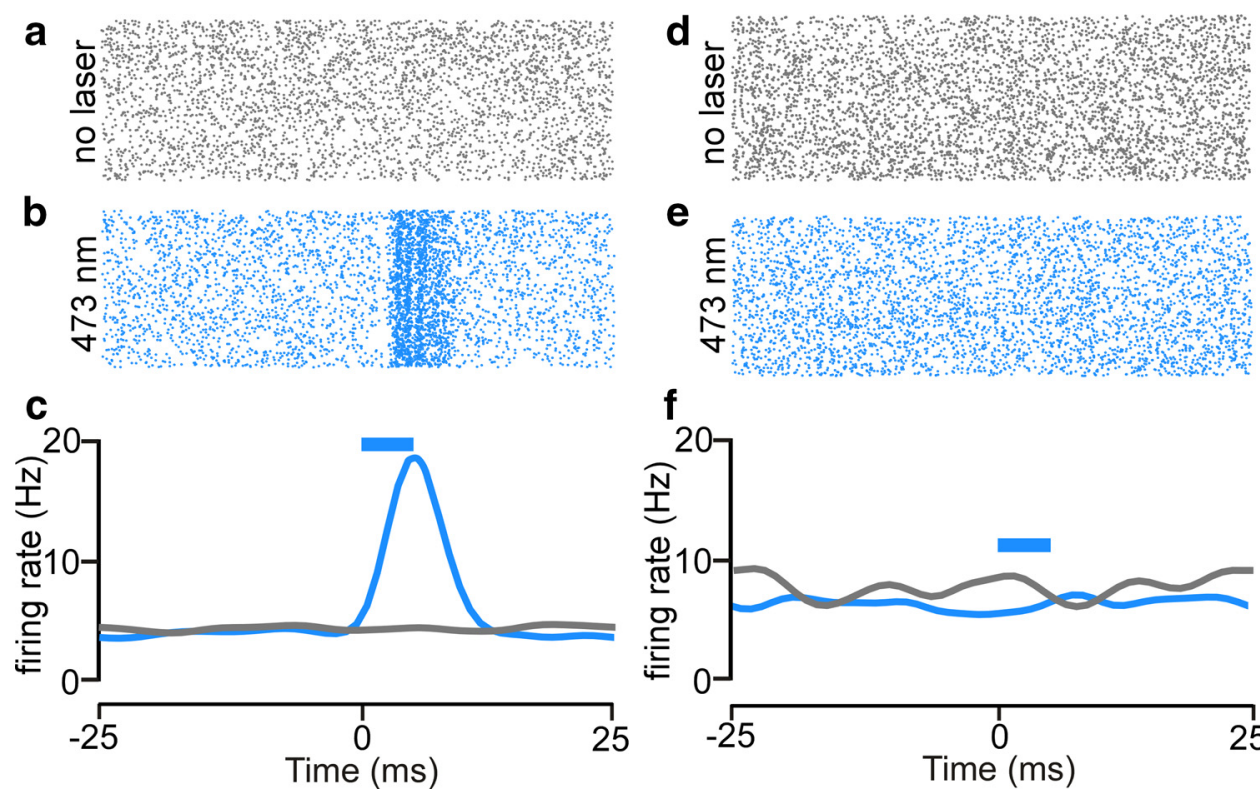

e

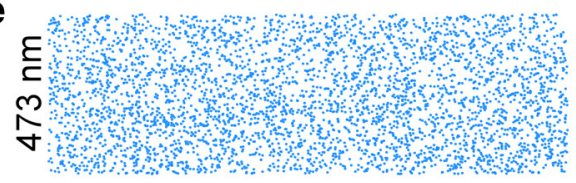

f

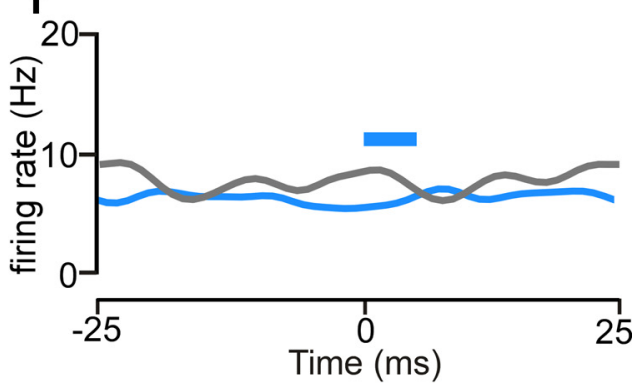

Figure 5. Neurophysiological confirmation of ChR2-mediated photoexcitation. $\boldsymbol{a}-\boldsymbol{c}$, Example of neurophysiological activity in the absence ( $\boldsymbol{a}$; gray raster plot, 15 min recording session) and presence ( $\boldsymbol{b}$; blue raster plot, $15 \mathrm{~min}$ recording session) of $20 \mathrm{~Hz}$ pulsed $473 \mathrm{~nm}$ light in a putative ChR2-expressing avBST unit with summary histogram (c) illustrating light-evoked neuronal activity. $\boldsymbol{d}-\boldsymbol{f}$, In a YFP-microinjected animal, firing rates unchanged between the unilluminated $(\boldsymbol{d})$ and $473 \mathrm{~nm}$ illuminated $(\boldsymbol{e})$ recording periods, which are summarized in a histogram $(\boldsymbol{f})$. Blue bars indicate 5 ms laser pulse.

Circuit analysis of the avBST-to-PVH pathway was undertaken in groups of rats bearing avBST microinjections either of AAV-Arch or AAV-YFP and fiber-optic probe placements above PVH (Fig. $7 a-c$ ). avBST terminals in PVH were illuminated with $561 \mathrm{~nm}$ light for a 30 min period beginning with TS and terminating $20 \mathrm{~min}$ after its conclusion. The decision to use a prolonged illumination period relative to the $10 \mathrm{~min}$ exposure period in the foregoing Arch somata experiment was made to ascertain whether inactivation of the avBST-to-PVH pathway after stress would more robustly enhance HPA output compared with avBST somata photoinhibition. Inactivation of avBST terminals in PVH increased stress-induced Fos expression in medial parvicellular PVH (Fig. $7 d, e)$. Counts of Fos-immunoreactive nuclei in PVH revealed a main effect of treatment $\left(F_{(2,9)}=24.9 ; p<0.05\right)$, with YFP and Arch groups showing significant Fos induction in $\mathrm{PVH}$ ( $p<0.05$ relative to unstressed YFP controls). Rats in the Arch group exhibited a substantial increase in Fos expression in $\mathrm{PVH}$ relative to stressed YFP counterparts (by 63\%, $p<0.05$; Fig. $7 f$ ).

In the same groups of rats, radioimmunoassay was performed for the analysis of HPA secretory responses. Mixed-design ANOVA for plasma levels of ACTH showed main effects of treatment $\left(F_{(1,14)}=6.2 ; p<0.05\right)$ and time $\left(F_{(4,56)}=89.3 ; p<0.05\right)$. Peak ACTH levels did not differ between groups $(10 \mathrm{~min}, p=$ $0.5)$, but were elevated in the Arch group at the 30,60, and 90 min time points ( $p<0.05$ for each; Fig. $7 g$ ). Results for plasma CORT paralleled that of ACTH, showing main effects for treatment $\left(F_{(1,14)}=9.6 ; p<0.05\right)$, time $\left(F_{(4,56)}=191.9 ; p<0.05\right)$, and the interaction $\left(F_{(4,56)}=5.2 ; p<0.05\right)$. Post hoc analyses at individual time points revealed enhancements in CORT levels in Arch rats at 30 and $60 \mathrm{~min}(p<0.05$ for each; Fig. $7 h)$. Area under the curve analyses for ACTH and CORT as a function of treatment also revealed augmented response profiles in Arch rats $(p<0.05$ for each). Finally, photoinhibition of avBST axons in PVH had no effect on immobility during TS relative to the YFP control group $(p=0.2$; Fig. $7 i)$.

\section{Photoinhibition of avBST terminal fields in vlPAG}

Whereas photoinhibition of avBST proper augmented stressinduced HPA activation and immobility to TS, the fact that photoinhibition of the axonal pathway to $\mathrm{PVH}$ produced effects limited to HPA end points suggests the involvement of dissociable circuitry from avBST to HPA and behavioral effector systems. Therefore, we sought to determine the behavioral outputs that mediate augmented immobility observed during avBST somata photoinhibition. Prior work has established that PAG regulates emotional coping responses under a range of challenges, with the dorsolateral and ventrolateral subdivisions involved in active and passive behavioral coping strategies, respectively (Carrive et al., 1997; Bandler et al., 2000; Keay and Bandler, 2001; Walker and Carrive, 2003; Brandão et al., 2008). Because the primary constituent subnuclei of avBST (i.e., fusiform and dorsomedial subdivisions of Dong et al., 2001, and Dong and Swanson, 2006) selectively innervate the vlPAG, we hypothesized that this GABAergic pathway inhibits passive coping during acute stress. To investigate this, we administered bilateral microinjections of AAV-Arch or AAV-YFP into the avBST and placed fiberoptic implants dorsal to avBST terminal fields in vlPAG (Fig. $8 a, b)$. After 6 weeks of recovery, rats were subjected to the same emotional stressor and blood collection procedures described previously. Histological analysis revealed dense avBST terminal fields in vlPAG and a majority (80\%) of YFP-fluorescent puncta colocalized with GAD-65 (Fig. $8 c-e$ ). Photoinhibition of the avBST-to-vlPAG pathway substantially increased immobility behavior during TS (by 150\%), expanding upon our previous observations after stimulation of Arch within the cell groups of origin in avBST ( $p<0.05$, Arch vs YFP group; Fig. $8 f$ ). In contrast, mixed-design ANOVA of ACTH and CORT failed to reveal any significant main effects or effects at any individual time point sampled (Fig. $8 g, h)$.

To examine the generality of the avBST-to-vlPAG pathway for modulating passive coping behaviors during stress, a separate 

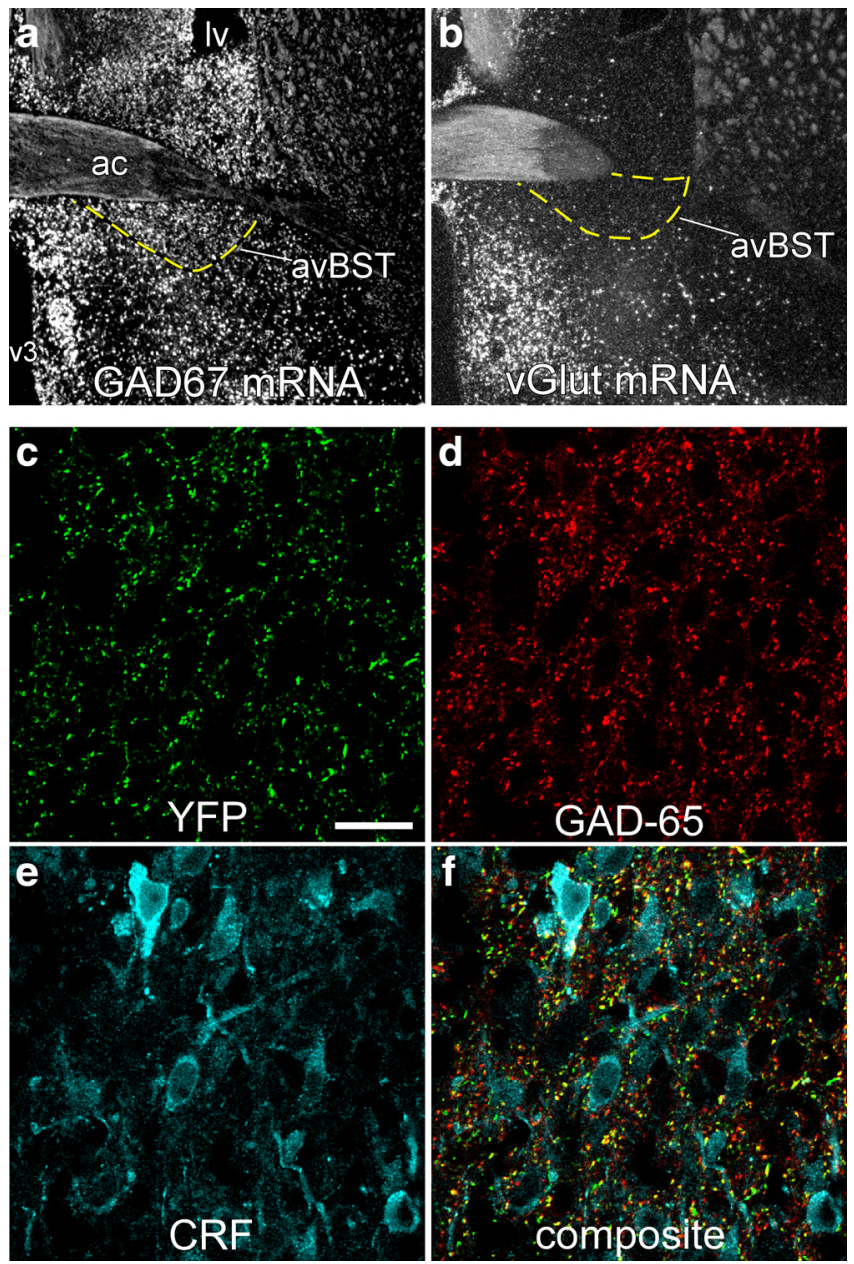

Figure 6. Phenotypic characterization of avBST neurons and terminal fields in PVH. $\boldsymbol{a}, \boldsymbol{b}$, Dark-field photomicrograph showing in situ hybridization of GAD67 (a) and VGLUT (b) mRNA in avBST and its vicinity. $\mathbf{c}-\boldsymbol{f}$, Confocal laser-scanning microscopic image displaying the distribution of YFP-fluorescent terminals (green) that originated from avBST (c) and corresponding images in the same z-section showing GAD-65 (d, red) and CRF (e, cyan) immunoreactivity $(\boldsymbol{f}$, composite). Scale bar, $400 \mu \mathrm{m}(\boldsymbol{a}, \boldsymbol{b}) ; 20 \mu \mathrm{m}(\boldsymbol{c}-\boldsymbol{f})$.

group of animals bearing either AAV-Arch or AAV-YFP microinjections into avBST and fiber-optic placement above vlPAG were subjected to a 10 min FS test coincident with $561 \mathrm{~nm}$ illumination. Arch animals spent significantly more time in a passive coping state compared with YFP controls (by 51\%, $p<0.05$; Fig. $9 a)$. Finally, we addressed the possibility that increased immobility in the TS and FS tests could arise from a general suppression of motor activity after inactivation of the avBST-to-vlPAG pathway. avBST neuron axons in vlPAG were inactivated with $561 \mathrm{~nm}$ light over the course of a $10 \mathrm{~min}$ exposure to a novel open-field chamber; however, no differences were observed in either velocity or distance traveled ( $p=0.88$ and 0.97 , respectively; Fig. $9 b, c$ ). Together, these experiments provide further evidence for the necessity of the avBST-to-vlPAG pathway in the inhibition of passive coping responses during acute stressor exposure.

\section{Discussion}

In the present study, we identified a novel role for a BST subregion involved in the coordinated modulation of neuroendocrine and behavioral responses to stress via divergent neural pathways to PVH and PAG. This conclusion is based upon our initial findings that silencing avBST cell bodies enhanced both HPA output and passive coping behavior, whereas stimulation of this cell group dampened central and hormonal indices of HPA output. Follow-up studies involving selective inactivation of avBST neuron axons in PVH and PAG highlighted dissociable pathways capable of modulating endocrine and behavioral components of stress responses. That avBST is singularly capable of restraining HPA output while inhibiting passive coping behaviors advances our understanding of how these functions are cooperatively regulated to optimize adaptive responses during stress (Fig. 10).

\section{Comparison with past studies}

At first glance, these results contrast with an expansive literature implicating the dorsal BST in the regulation of responses to sustained threats and/or contextual fear conditioning collectively likened to "anxiety" (Walker and Davis, 1997; Walker et al., 2003; Sullivan et al., 2004; Davis et al., 2010; Kim et al., 2013). Our results may help to dissociate BST circuitry in terms of approach avoidance from passive coping behavioral responses distributed in dorsal and ventral subregions, respectively. Relative to dorsal BST (i.e., the nuclei dorsal to the anterior commissure), the ventral subdivisions receive a wider array of inputs from cell groups important for emotional regulation (e.g., medial prefrontal cortex, ventral subiculum, paraventricular thalamus) and are further differentiated from their dorsal counterparts by issuing efferent projections to neuroendocrine effector cell groups in the hypothalamus (Dong et al., 2001; Dong and Swanson, 2006; Radley and Sawchenko, 2011). That our results are consistent with an extensive literature implicating BST in slower-onset and protracted responses to sustained threats (Walker et al., 2003; Davis et al., 2010) highlights an overarching theme for understanding how BST modulates adaptive responses over a broad range of environmental challenges. Similarly, our optogenetic manipulations of avBST had a modulatory effect on HPA and behavioral coping responses to stress. Photoinhibition of avBST significantly potentiated HPA activation and increased immobility during inescapable stress exposure compared with more nominal effects that were limited to the inhibition of HPA output after photoexcitation.

Studies have observed robust immediate-early gene induction and increased synaptic activation in avBST neurons after acute stress exposure (Cullinan et al., 1995; Li and Sawchenko, 1998; Campeau and Watson, 2000; Spencer et al., 2005; McElligott et al., 2010; Radley and Sawchenko, 2011; Glangetas et al., 2013; Daniel and Rainnie, 2016). Taken with our current results, these studies indicate that avBST and related circuitry are prominently engaged by acute challenges while remaining largely uninvolved in tonic regulation of the HPA axis. Nevertheless, because there has been some indication that anterior BST lesions may produce at least a mild enhancement of basal HPA activity (Herman et al., 1994; cf. Choi et al., 2007; Radley et al., 2009; Radley and Sawchenko, 2011), further studies are needed to address the potential contributions of BST subregions in the circadian modulation of HPA activity.

avBST pathway modulation of passive coping during stress To our knowledge, this is the first study to elucidate a descending pathway from avBST to vlPAG in the inhibition of passive coping behaviors (i.e., decreased immobility during TS and FS tests). One might speculate that inactivation of this pathway increased immobility by inhibiting active, rather than disinhibiting passive, coping responses. However, such an interpretation deviates from considerable evidence that PAG functions are parcellated in longitudinal columns, with lateral/dorsolateral and ventrolateral as- 
a
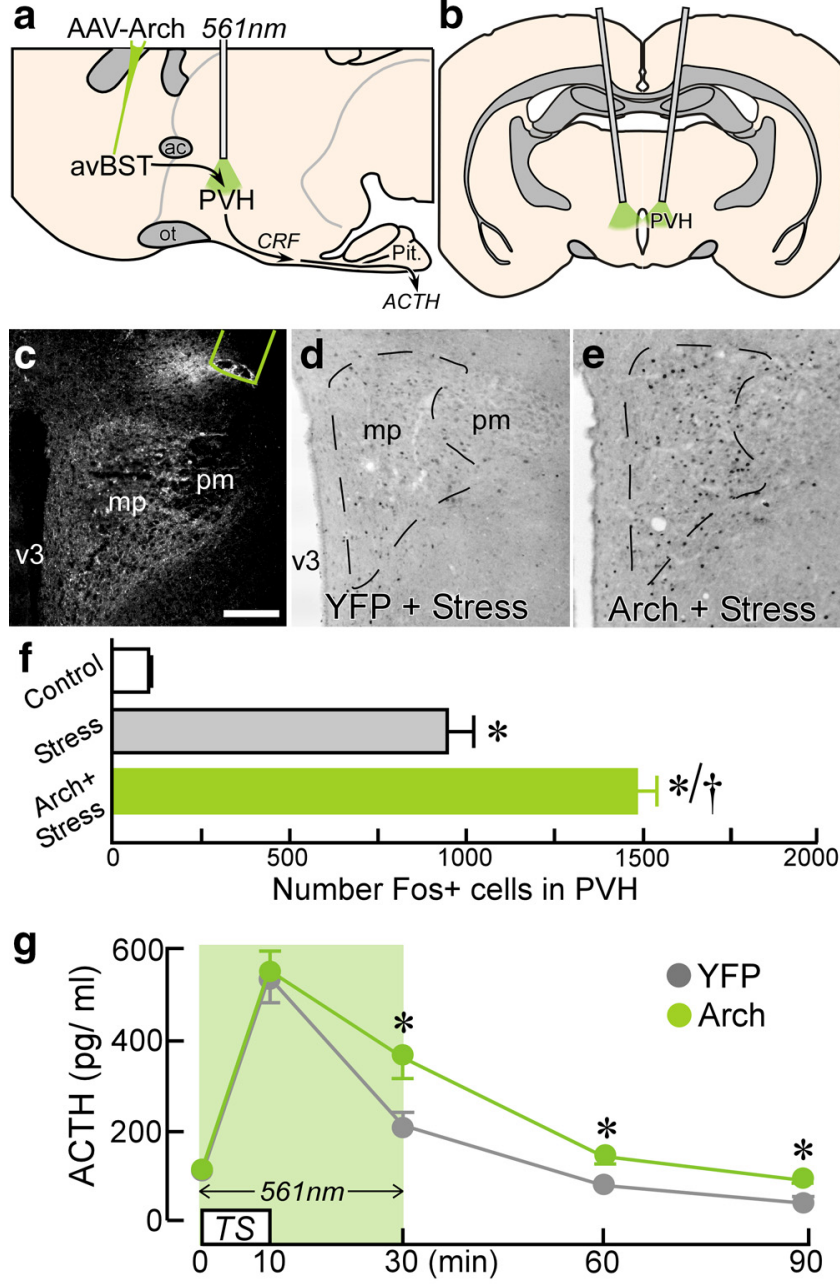

h

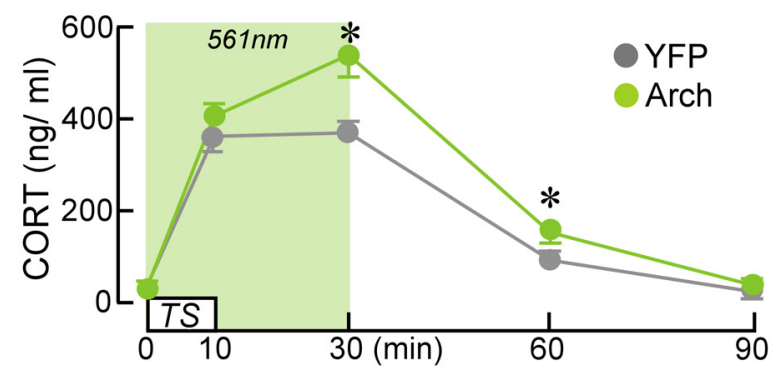

i

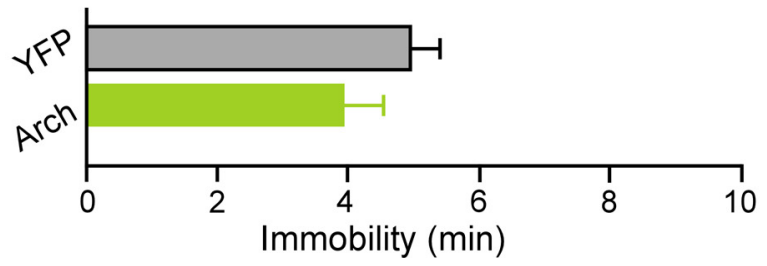

Figure 7. Selective consequences of avBST-to-PVH pathway photoinhibition on HPA output. $\boldsymbol{a}, \boldsymbol{b}$, Sagittal schematic diagram depicting AAV-Arch microinjection into avBST (a) and bilateral fiber optic probe implantation dorsal to avBST terminal fields in PVH (right, coronal view; $\boldsymbol{b}$ ). c, Dark-field photomicrograph depicting fiber-optic termination (green outline) above YFPfluorescent avBST terminals in the medial parvicellular (mp) and posterior magnocellular (pm) PVH. $\boldsymbol{d}, \boldsymbol{e}$, Photomicrographs showing immunoperoxidase labeling of Fos in PVH from a YFP rat subjected to TS and the marked increase in immunoreactivity after avBST terminal photoinhibition. Scale bar, $200 \mu \mathrm{m}(\mathbf{c}-\boldsymbol{e})$. $\boldsymbol{f}$, Quantification of Fos-immunoreactive nuclei reveals a significant induction as a result of stress exposure $\left(^{*} p<0.05\right)$ and further enhancement after photoinhibition of avBST neuron axons $(t p<0.05) . n=2$ YFP + control, $n=5$ YFP + stress, $n=5$ Arch + stress. $g$, ACTH levels in YFP and Arch groups before and after $10 \mathrm{~min}$ TS coincident and followed by $561 \mathrm{~nm}$ illumination of avBST terminals in PVH, with significant elevations pects mediating active and passive coping responses to stress, respectively (Keay and Bandler, 2001). Because most of the efferents from avBST to PAG are GABAergic and terminate preferentially within the ventrolateral subdivision, inactivating this pathway likely disengages the inhibitory influence on passive coping that is normally provided during acute stress. Evidence for exclusivity of the avBST-to-vlPAG pathway in modulating only passive coping behavior derives largely from our observation that inhibition of avBST cell bodies augmented both HPA output and immobility, whereas inhibition of the avBST axonal pathway in vlPAG increased only immobility, during TS. Although the vlPAG has been shown to send projections to PVH proper (Floyd et al., 1996; Ziegler et al., 2012), the lack of any precedent for this pathway's involvement in stress-induced HPA modulation and our data argue against any bidirectional or closed circuit relationship between behavioral coping and endocrine modulation through pathways involving avBST.

The increase in immobility that we observed after inactivation of avBST neuron axons in vlPAG was apparent in both TS and FS tests. The involvement of the avBST-to-vlPAG pathway in modulating behavioral coping responses merits further consideration of its role in depression-like behaviors because these tests are used widely to screen antidepressant drug efficacy by the assessment of their ability to decrease immobility (Porsolt et al., 1977; Steru et al., 1985; Chermat et al., 1986). From this perspective, activation of the avBST-to-vlPAG pathway during inescapable challenges has the potential to protect against a depression-related behavioral end point or, conversely, that dysregulation could contribute to pathological features related to mood disorders. Indeed, it has been known for several decades that the serotonin-containing dorsal and median raphe nuclei innervate avBST (Köhler and Steinbusch, 1982; Molliver, 1987; Shin et al., 2008); however, the functional role of this pathway remains to be examined critically.

\section{Characteristics of avBST modulation of HPA activation}

Photoinhibition of avBST terminal fields in PVH augmented central (Fos induction in $\mathrm{PVH}$ ) and hormonal (plasma ACTH and CORT) indices of stress-induced HPA output, supporting our anatomical observations that this pathway is GABAergic. These results also extend the foregoing radioimmunometric experiments in which stimulation and inhibition of avBST, respectively, dampened and augmented stress-induced HPA activation. Our data clarify previous attempts to sort out the role of avBST in stress regulation-an issue hampered by cell-type heterogeneity and complex connectivity patterns in this anatomical brain region (Dunn, 1987; Herman et al., 1994; Cecchi et al., 2002; Choi et al., 2007; Radley and Sawchenko, 2011; Daniel and Rainnie, 2016; Lebow and Chen, 2016). Whereas recent work indicates that avBST itself contains a heterogeneous group of excitatory and inhibitory neurons (Jennings et al., 2013), our results do not support any such differentiation with respect to avBST efferents to PVH (Fig. 3g,h).

One lingering question concerns the temporal relationship between avBST activation and alteration of PVH/ HPA output during stress. In our initial experiments, avBST somata photoinhibition for $10 \mathrm{~min}$ given concurrent with the stress challenge

$\leftarrow$

observed 30, 60, and 90 min after stress onset $\left({ }^{*} p<0.05\right)$. $\boldsymbol{h}$, CORT levels from the same groups in e showing significant elevations at 30 and $60 \mathrm{~min}$ in the Arch group versus YFP controls $\left({ }^{*} p<0.05\right)$. $\boldsymbol{i}$, Immobility during TS was not significantly different between groups $(p=0.2) . n=9$ YFP, $n=7 \operatorname{Arch}(\boldsymbol{f}-\boldsymbol{i})$. 

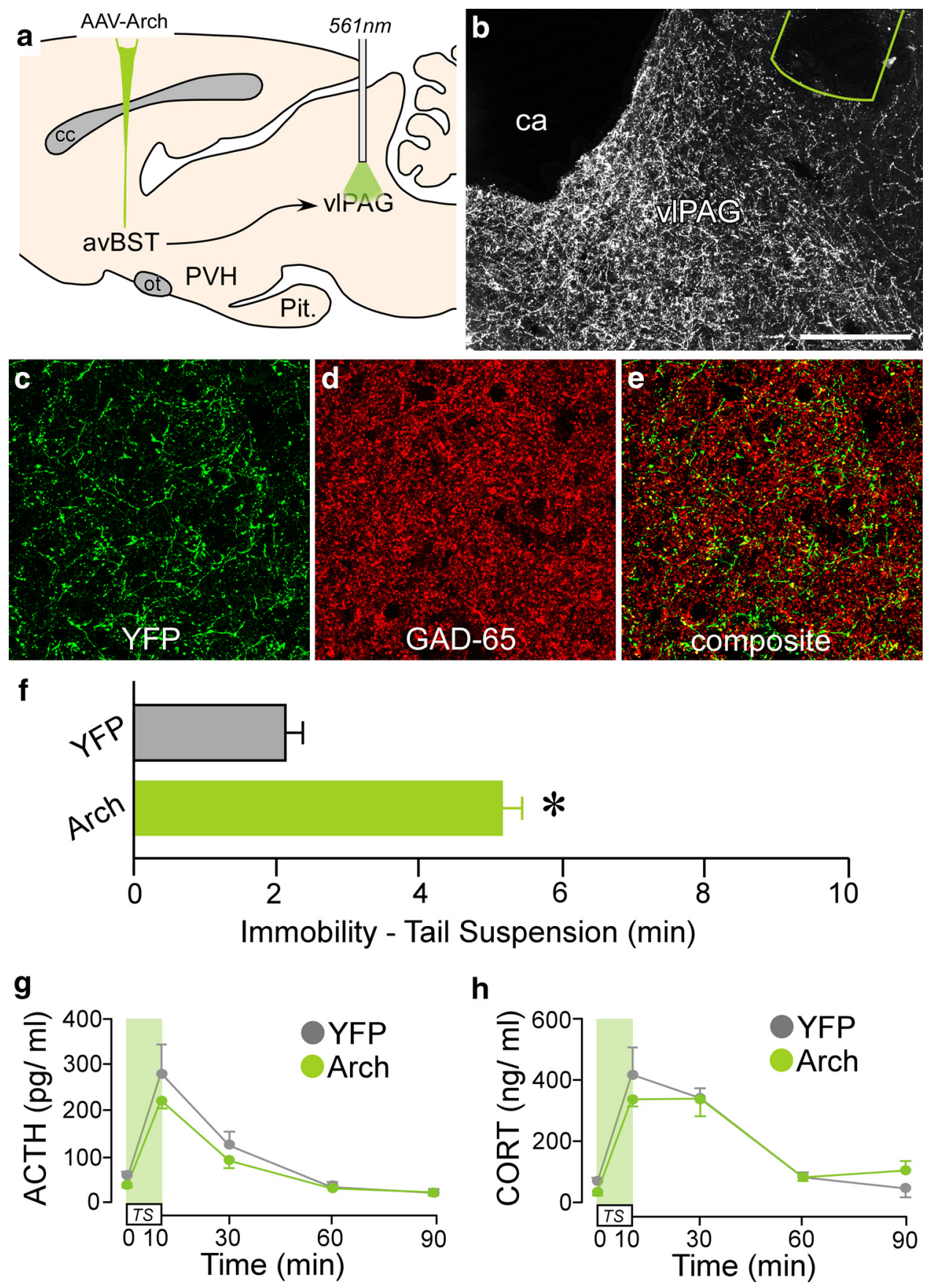

\section{0}

h

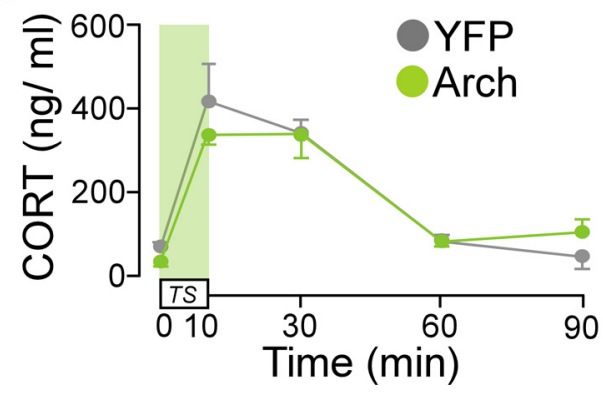

Figure 8. Selective behavioral consequences after avBST-to-vIPAG pathway photoinhibition. $\boldsymbol{a}$, Schematic diagram depicting AAV-Arch microinjection into avBST and fiber-optic probe placement above its terminal fields in the ventrolateral periaqueductal gray (vIPAG). $\boldsymbol{b}$, Dark-field photomicrograph showing fiber-optic probe (green outline) placement above a YFP-fluorescent terminal plexus originating from avBST. ca, Cerebral aqueduct. $c-\boldsymbol{e}$, Digital reconstructions of YFP-fluorescent axonal and terminal fields in vIPAG (green, $c$ ) and colocalization with GAD-65 immunofluorescent terminals (red, $\boldsymbol{d}$; overlap in $\boldsymbol{e}$ ). Scale bar, $200 \mu \mathrm{m}(\boldsymbol{b}) ; 40 \mu \mathrm{m}(\boldsymbol{c}-\boldsymbol{e})$. $\boldsymbol{f}-\boldsymbol{h}$, Bilateral photoinhibition of avBST neuron axons in vIPAG during TS $(\boldsymbol{f})$ led to a marked increase in immobility behavior $\left({ }^{*} p<0.05\right)$, whereas radioimmunoassay of ACTH $(\boldsymbol{g})$ and CORT levels $(\boldsymbol{h})$ in YFP and Arch animals failed to reveal any significant differences in HPA activation. $n=5$ YFP, $n=6$ Arch $(\boldsymbol{f}-\boldsymbol{h})$.

manifested in an extension of pituitary-adrenal responses evident after the illumination period (i.e., 30 min time point in Fig. $1 g, h)$. In our follow-up experiment, extending the inhibition of avBST terminals in PVH proper to 30 min resulted in an even longer poststress elevation of stress-induced hormonal indices (i.e., at 30, 60, and 90 min time points in Fig. $7 g, h$ ). Whereas direct comparison of these studies is confounded by the different circuit elements inactivated (cell bodies vs axon terminals) and duration of photoinhibition (10 vs $30 \mathrm{~min}$ ), neither manipulation enhanced the magnitude of HPA output and the effects of inactivation were not evident until the aftermath of stress. Such a delay is consistent with the widely documented phenomenon that the duration, rather than magnitude, of stress-induced HPA activation is enhanced after lesioning/inactivation in a variety of limbic forebrain cell groups (for review, see Ulrich-Lai and Herman, 2009; Radley, 2012). However, our results suggest that activation of the avBST(GABA)-to-PVH circuit within the first few minutes of stress exposure is capable of restricting the duration of HPA output after the challenge has subsided. Activation of this pathway may facilitate rapid (i.e., nongenomic) glucocorticoid 
a

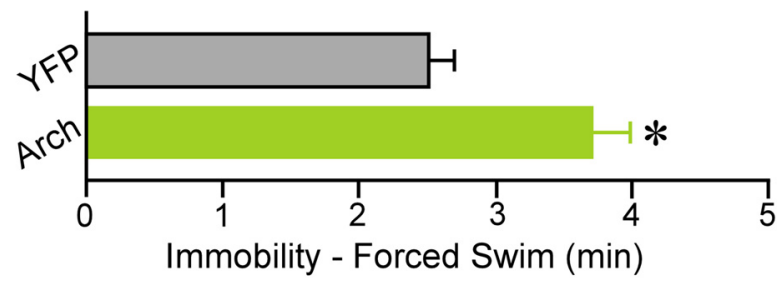

b
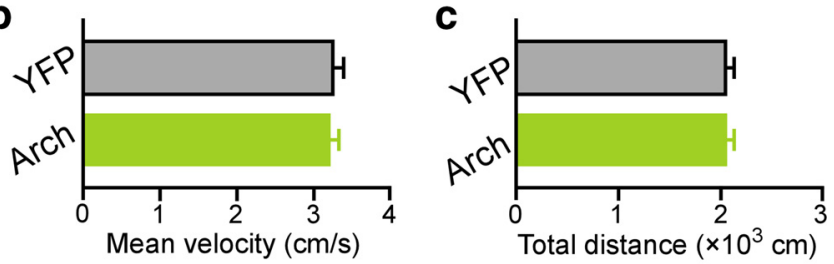

Locomotor activity

Figure 9. Consequences of avBST-to-vIPAG photoinhibition generalize to $\mathrm{FS}$ behavior, but not locomotor activity. $\boldsymbol{a}$, Behaviorally naive animals bearing AAV-YFP or AAV-Arch microinjections in avBST and fiber-optic placements above vIPAG were subjected to the FS test and $561 \mathrm{~nm}$ illumination of avBST terminals in vIPAG, revealing a significant increase in immobility in Arch animals relative to YFP rats ( $\left.{ }^{*} p<0.05\right) . \boldsymbol{b}, \boldsymbol{c}$, Assessment of locomotor activity for 10 min concurrent with $561 \mathrm{~nm}$ illumination revealed no differences between groups in either mean velocity $(\boldsymbol{b})$ or total distance traveled $(\boldsymbol{c})(p=0.88$ and 0.97 , respectively). $n=6$ per group $(\boldsymbol{a}-\boldsymbol{c})$.

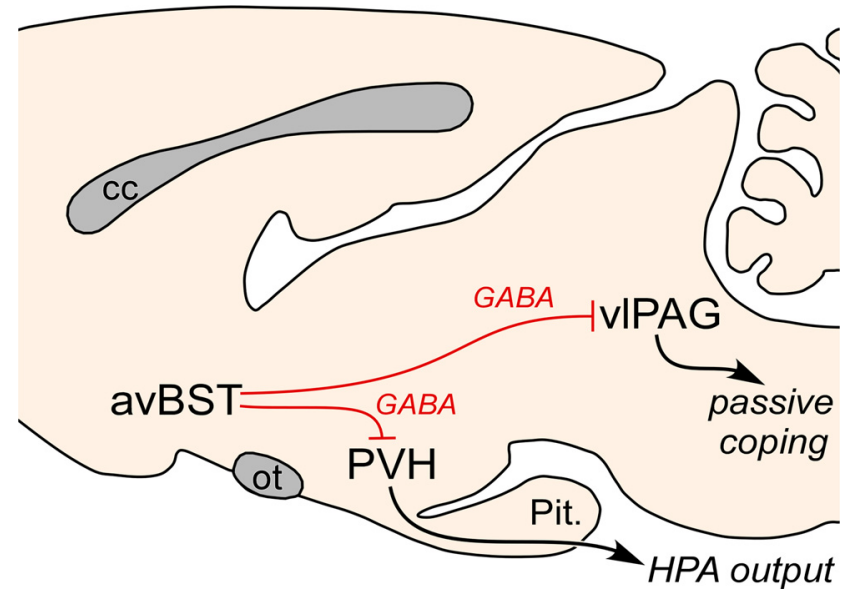

Figure 10. Summary diagram highlighting the role of avBST in the coordination of behavioral and neuroendocrine responses to stress. The data support the pathways highlighted in red, with avBST providing inhibitory control over (1) HPA effector neurons in PVH and (2) passive coping circuits centered within the vIPAG.

receptor-mediated feedback at the level of PVH (Ginsberg et al., 2003; Dallman, 2005; Tasker and Herman, 2011; Keller-Wood, 2015) or it may alter metaplasticity in parvicellular neurons in a manner not easily detected with the current set of approaches (Bains et al., 2015). Future studies are needed to better understand the cellular alterations that account for circuit-mediated influences on stress-induced modulation of HPA activity.

\section{Anatomical organization of avBST circuitry}

To our knowledge, this is the first study showing that the avBST modulates endocrine and behavioral coping via divergent anatomical pathways. Evidence that these functions involve dissociable pathways is based on the observation that inactivation of individual circuit elements in different experiments, that is, from avBST-to-PVH and avBST-to-vlPAG, led to an enhancement of only the respective HPA or passive behavioral coping components of the stress response. Although it is tempting to speculate that these functions are subserved by distinct cell groups within avBST, the possibility remains that a single group of cells issues axon collaterals to both regions. Further work will investigate both the anatomical and topographical organization of avBST cell groups that modulate endocrine and behavioral responses and the differential innervation patterns that these cell groups receive from the limbic forebrain.

\section{Functional considerations}

The teleological significance of such a coordination of stress responses is not well understood, although one intriguing idea is that avBST inhibits passive coping to promote escaping from the threat at hand and thereafter adaptively limits glucocorticoid exposure. Indeed, there is some precedent for an analogous relationship between HPA and behavioral output, with a tendency of passive or reactive coping styles to be associated with higher HPA-axis reactivity relative to counterparts that adopt more active coping strategies (Veenema et al., 2003; Koolhaas, 2008; Walker et al., 2009). These data also raise the possibility that the differential engagement of avBST and related circuitry may underlie phenotypes commonly considered as "resilient" or "vulnerable" in the stress research field. Several repeated-stress paradigms in rodents have been shown to produce depressionlike symptoms such as increased passive coping and HPA reactivity (for review, see Nestler and Hyman, 2010), which warrants more careful examination of avBST involvement in individual variations of stress reactivity and/or alterations in response to chronic conditions.

\section{References}

Bains JS, Wamsteeker Cusulin JI, Inoue W (2015) Stress-related synaptic plasticity in the hypothalamus. Nat Rev Neurosci 16:377-388. CrossRef Medline

Bandler R, Keay KA, Floyd N, Price J (2000) Central circuits mediating patterned autonomic activity during active vs. passive emotional coping. Brain Res Bull 53:95-104. CrossRef Medline

Brandão ML, Zanoveli JM, Ruiz-Martinez RC, Oliveira LC, LandeiraFernandez J (2008) Different patterns of freezing behavior organized in the periaqueductal gray of rats: Association with different types of anxiety. Behav Brain Res 188:1-13. CrossRef Medline

Brown MR, Rivier C, Vale W (1984) Central nervous system regulation of adrenocorticotropin secretion: role of somatostatins. Endocrinology 114: 1546-1549. CrossRef Medline

Campeau S, Watson SJ Jr (2000) Connections of some auditory-responsive posterior thalamic nuclei putatively involved in activation of the hypothalamo-pituitary-adrenocortical axis in response to audiogenic stress in rats: an anterograde and retrograde tract tracing study combined with Fos expression. J Comp Neurol 423:474-491. Medline

Carrive P, Leung P, Harris J, Paxinos G (1997) Conditioned fear to context is associated with increased fos expression in the caudal ventrolateral region of the midbrain periaqueductal gray. Neuroscience 78:165-177. CrossRef Medline

Casada JH, Dafny N (1991) Restraint and stimulation of bed nucleus of the stria terminalis produce similar stress-like behaviors. Brain Res Bull 27: 207-212. CrossRef Medline

Cecchi M, Khoshbouei H, Javors M, Morilak DA (2002) Modulatory effects of norepinephrine in the lateral bed nucleus of the stria terminalis on behavioral and neuroendocrine responses to acute stress. Neuroscience 112:13-21. CrossRef Medline

Chermat R, Thierry B, Mico JA, Steru L, Simon P (1986) Adaptation of the tail suspension test to the rat. J Pharmacol 17:348-350. Medline

Choi DC, Furay AR, Evanson NK, Ostrander MM, Ulrich-Lai YM, Herman JP (2007) Bed nucleus of the stria terminalis subregions differentially regulate hypothalamic-pituitary-adrenal axis activity: Implications for the integration of limbic inputs. J Neurosci 27:2025-2034. CrossRef Medline

Choi DC, Evanson NK, Furay AR, Ulrich-Lai YM, Ostrander MM, Herman JP (2008) The anteroventral bed nucleus of the stria terminalis differentially 
regulates hypothalamic-pituitary-adrenocortical axis responses to acute and chronic stress. Endocrinology 149:818-826. CrossRef Medline

Cryan JF, Valentino RJ, Lucki I (2005) Assessing substrates underlying the behavioral effects of antidepressants using the modified rat forced swimming test. Neurosci Biobehav Rev 29:547-569. CrossRef Medline

Cullinan WE, Herman JP, Watson SJ (1993) Ventral subicular interaction with the hypothalamic paraventricular nucleus: evidence for a relay in the bed nucleus of the stria terminalis. J Comp Neurol 332:1-20. CrossRef Medline

Cullinan WE, Herman JP, Battaglia DF, Akil H, Watson SJ (1995) Pattern and time course of immediate early gene expression in rat brain following acute stress. Neuroscience 64:477-505. CrossRef Medline

Dallman MF (2005) Fast glucocorticoid actions on brain: back to the future. Front Neuroendocrinol 26:103-108. CrossRef Medline

Daniel SE, Rainnie DG (2016) Stress modulation of opposing circuits in the bed nucleus of the stria terminalis. Neuropsychopharmacology 41: 103-125. CrossRef Medline

Davis M, Walker DL, Miles L, Grillon C (2010) Phasic vs sustained fear in rats and humans: role of the extended amygdala in fear vs anxiety. Neuropsychopharmacology 35:105-135. CrossRef Medline

Detke MJ, Lucki I (1996) Detection of serotonergic and noradrenergic antidepressants in the rat forced swimming test: the effects of water depth. Behav Brain Res 73:43-46. Medline

Dong HW, Swanson LW (2006) Projections from bed nuclei of the stria terminalis, dorsomedial nucleus: Implications for cerebral hemisphere integration of neuroendocrine, autonomic, and drinking responses. J Comp Neurol 494:75-107. CrossRef Medline

Dong HW, Petrovich GD, Watts AG, Swanson LW (2001) Basic organization of projections from the oval and fusiform nuclei of the bed nuclei of the stria terminalis in adult rat brain. J Comp Neurol 436:430-455. CrossRef Medline

Drevets WC, Price JL, Simpson JR Jr, Todd RD, Reich T, Vannier M, Raichle ME (1997) Subgenual prefrontal cortex abnormalities in mood disorders. Nature 386:824-827. CrossRef Medline

Dunn JD (1987) Differential plasma corticosterone responses to electrical stimulation of the medial and lateral septal nuclei. Neuroendocrinology 46:406-411. Medline

Ericsson A, Kovács KJ, Sawchenko PE (1994) A functional anatomical analysis of central pathways subserving the effects of interleukin-1 on stressrelated neuroendocrine neurons. J Neurosci 14:897-913. Medline

Erlander MG, Tillakaratne NJ, Feldblum S, Patel N, Tobin AJ (1991) Two genes encode distinct glutamate decarboxylases. Neuron 7:91-100.

Floyd NS, Keay KA, Arias CM, Sawchenko PE, Bandler R (1996) Projections from the ventrolateral periaqueductal gray to endocrine regulatory subdivisions of the paraventricular nucleus of the hypothalamus in the rat. Neurosci Lett 220:105-108. CrossRef Medline

Ginsberg AB, Campeau S, Day HE, Spencer RL (2003) Acute glucocorticoid pretreatment suppresses stress-induced hypothalamic-pituitary-adrenal axis hormone secretion and expression of corticotropin-releasing hormone hnRNA but does not affect c-fos mRNA or fos protein expression in the paraventricular nucleus of the hypothalamus. J Neuroendocrinol 15: 1075-1083. CrossRef Medline

Glangetas C, Girard D, Groc L, Marsicano G, Chaouloff F, Georges F (2013) Stress switches cannabinoid type-1 (CB1) receptor-dependent plasticity from LTD to LTP in the bed nucleus of the stria terminalis. J Neurosci 33:19657-19663. CrossRef Medline

Herman JP, Cullinan WE, Watson SJ (1994) Involvement of the bed nucleus of the stria terminalis in tonic regulation of paraventricular hypothalamic Crh and Avp messenger RNA expression. J Neuroendocrinol 6:433-442. CrossRef Medline

Herman JP, Adams D, Prewitt C (1995) Regulatory changes in neuroendocrine stress-integrative circuitry produced by a variable stress paradigm. Neuroendocrinology 61:180-190. Medline

Hill MN, McLaughlin RJ, Pan B, Fitzgerald ML, Roberts CJ, Lee TT, Karatsoreos IN, Mackie K, Viau V, Pickel VM, McEwen BS, Liu QS, Gorzalka BB, Hillard CJ (2011) Recruitment of prefrontal cortical endocannabinoid signaling by glucocorticoids contributes to termination of the stress response. J Neurosci 31:10506-10515. CrossRef Medline

Huff ML, Miller RL, Deisseroth K, Moorman DE, LaLumiere RT (2013) Posttraining optogenetic manipulations of basolateral amygdala activity modulate consolidation of inhibitory avoidance memory in rats. Proc Natl Acad Sci U S A 110:3597-3602.
Izumi J, Washizuka M, Hayashi-Kuwabara Y, Yoshinaga K, Tanaka Y, Ikeda Y, Kiuchi Y, Oguchi K (1997) Evidence for a depressive-like state induced by repeated saline injections in Fischer 344 rats. Pharmacol Biochem Behav 57:883-888. CrossRef Medline

Jennings JH, Sparta DR, Stamatakis AM, Ung RL, Pleil KE, Kash TL, Stuber GD (2013) Distinct extended amygdala circuits for divergent motivational states. Nature 496:224-228. CrossRef Medline

Keay KA, Bandler R (2001) Parallel circuits mediating distinct emotional coping reactions to different types of stress. Neurosci Biobehav Rev 25: 669-678. CrossRef Medline

Keller-Wood M (2015) Hypothalamic-pituitary-adrenal axis feedback control. Compr Physiol 5:1161-1182. CrossRef Medline

Kim SY, Adhikari A, Lee SY, Marshel JH, Kim CK, Mallory CS, Lo M, Pak S, Mattis J, Lim BK, Malenka RC, Warden MR, Neve R, Tye KM, Deisseroth K (2013) Diverging neural pathways assemble a behavioural state from separable features in anxiety. Nature 496:219-223. CrossRef Medline

Köhler C, Steinbusch H (1982) Identification of serotonin and nonserotonin-containing neurons of the mid-brain raphe projecting to the entorhinal area and the hippocampal formation: a combined immunohistochemical and fluorescent retrograde tracing study in the rat brain. Neuroscience 7:951-975. CrossRef Medline

Koolhaas JM (2008) Coping style and immunity in animals: making sense of individual variation. Brain Behav Immun 22:662-667. CrossRef Medline

Lebow MA, Chen A (2016) Overshadowed by the amygdala: the bed nucleus of the stria terminalis emerges as key to psychiatric disorders. Mol Psychiatry 21:450-463. CrossRef Medline

Li HY, Sawchenko PE (1998) Hypothalamic effector neurons and extended circuitries activated in "neurogenic" stress: a comparison of footshock effects exerted acutely, chronically, and in animals with controlled glucocorticoid levels. J Comp Neurol 393:244-266. Medline

MacQueen G, Frodl T (2011) The hippocampus in major depression: evidence for the convergence of the bench and bedside in psychiatric research? Mol Psychiatry 16:252-264. CrossRef Medline

McElligott ZA, Klug JR, Nobis WP, Patel S, Grueter BA, Kash TL, Winder DG (2010) Distinct forms of Gq-receptor-dependent plasticity of excitatory transmission in the BNST are differentially affected by stress. Proc Natl Acad Sci U S A 107:2271-2276. CrossRef Medline

Molliver ME (1987) Serotonergic neuronal systems: what their anatomic organization tells us about function. J Clin Psychopharmacol 7:3S-23S. CrossRef Medline

Nestler EJ, Hyman SE (2010) Animal models of neuropsychiatric disorders. Nat Neurosci 13:1161-1169. CrossRef Medline

Paumier KL, Sortwell CE, Madhavan L, Terpstra B, Celano SL, Green JJ, Imus NM, Marckini N, Daley B, Steece-Collier K, Collier TJ (2015) Chronic amitriptyline treatment attenuates nigrostriatal degeneration and significantly alters trophic support in a rat model of parkinsonism. Neuropsychopharmacology 40:874-883. CrossRef Medline

Porsolt RD, Le Pichon M, Jalfre M (1977) Depression: a new animal model sensitive to antidepressant treatments. Nature 266:730-732. CrossRef Medline

Price JL, Drevets WC (2012) Neural circuits underlying the pathophysiology of mood disorders. Trends Cogn Sci 16:61-71. CrossRef Medline

Radley JJ (2012) Toward a limbic cortical inhibitory network: implications for hypothalamic-pituitary-adrenal responses following chronic stress. Front Behav Neurosci 6:7. CrossRef Medline

Radley JJ, Sawchenko PE (2011) A common substrate for prefrontal and hippocampal inhibition of the neuroendocrine stress response. J Neurosci 31:9683-9695. CrossRef Medline

Radley JJ, Sawchenko PE (2015) Evidence for involvement of a limbic paraventricular hypothalamic inhibitory network in hypothalamicpituitary-adrenal axis adaptations to repeated stress. J Comp Neurol 523: 2769-2787.

Radley JJ, Arias CM, Sawchenko PE (2006) Regional differentiation of the medial prefrontal cortex in regulating adaptive responses to acute emotional stress. J Neurosci 26:12967-12976. CrossRef Medline

Radley JJ, Williams B, Sawchenko PE (2008) Noradrenergic innervation of the dorsal medial prefrontal cortex modulates hypothalamo-pituitaryadrenal responses to acute emotional stress. J Neurosci 28:5806-5816. CrossRef Medline

Radley JJ, Gosselink KL, Sawchenko PE (2009) A discrete GABAergic relay mediates medial prefrontal cortical inhibition of the neuroendocrine stress response. J Neurosci 29:7330-7340. CrossRef Medline 
Radley JJ, Anderson RM, Hamilton BA, Alcock JA, Romig-Martin SA (2013) Chronic stress-induced alterations of dendritic spine subtypes predict functional decrements in an hypothalamo-pituitary-adrenal-inhibitory prefrontal circuit. J Neurosci 33:14379-14391. CrossRef Medline

Sawchenko P, Cunningham E Jr, Mortrud M, Pfeiffer S, Gerfen C (1990) Phaseolus vulgaris leucoagglutinin (PHA-L) anterograde axonal transport technique. Methods in Neurosciences 3:247-260. CrossRef

Sheline YI, Wang PW, Gado MH, Csernansky JG, Vannier MW (1996) Hippocampal atrophy in recurrent major depression. Proc Natl Acad Sci U S A 93:3908-3913. CrossRef Medline

Shin JW, Geerling JC, Loewy AD (2008) Inputs to the ventrolateral bed nucleus of the stria terminalis. J Comp Neurol 511:628-657. CrossRef Medline

Simmons DM, Arriza JL, Swanson L (1989) A complete protocol for in situ hybridization of messenger RNAs in brain and other tissues with radiolabeled single-stranded RNA probes. Journal of Histotechnology 12: 169-181. CrossRef

Spencer SJ, Buller KM, Day TA (2005) Medial prefrontal cortex control of the paraventricular hypothalamic nucleus response to psychological stress: possible role of the bed nucleus of the stria terminalis. J Comp Neurol 481:363-376. CrossRef Medline

Steru L, Chermat R, Thierry B, Simon P (1985) The tail suspension test: a new method for screening antidepressants in mice. Psychopharmacology 85:367-370. CrossRef Medline

Stone EA, Lin Y, Sarfraz Y, Quartermain D (2011) Antidepressant-like action of intracerebral 6-fluoronorepinephrine, a selective full alphaadrenoceptor agonist. Int J Neuropsychopharmacol 14:319-331. CrossRef Medline

Strekalova T, Spanagel R, Bartsch D, Henn FA, Gass P (2004) Stress-induced anhedonia in mice is associated with deficits in forced swimming and exploration. Neuropsychopharmacology 29:2007-2017. CrossRef Medline

Sullivan GM, Apergis J, Bush DE, Johnson LR, Hou M, Ledoux JE (2004) Lesions in the bed nucleus of the stria terminalis disrupt corticosterone and freezing responses elicited by a contextual but not by a specific cueconditioned fear stimulus. Neuroscience 128:7-14. CrossRef Medline

Tasker JG, Herman JP (2011) Mechanisms of rapid glucocorticoid feedback inhibition of the hypothalamic-pituitary-adrenal axis. Stress 14:398-406. CrossRef Medline
Ulrich-Lai YM, Herman JP (2009) Neural regulation of endocrine and autonomic stress responses. Nat Rev Neurosci 10:397-409. CrossRef Medline

Veenema AH, Meijer OC, de Kloet ER, Koolhaas JM, Bohus BG (2003) Differences in basal and stress-induced HPA regulation of wild house mice selected for high and low aggression. Horm Behav 43:197-204. CrossRef Medline

Videbech P, Ravnkilde B (2004) Hippocampal volume and depression: A meta-analysis of MRI studies. Am J Psychiat 161:1957-1966. CrossRef Medline

Walker DL, Davis M (1997) Double dissociation between the involvement of the bed nucleus of the stria terminalis and the central nucleus of the amygdala in startle increases produced by conditioned versus unconditioned fear. J Neurosci 17:9375-9383. Medline

Walker DL, Toufexis DJ, Davis M (2003) Role of the bed nucleus of the stria terminalis versus the amygdala in fear, stress, and anxiety. Eur J Pharmacol 463:199-216. CrossRef Medline

Walker FR, Masters LM, Dielenberg RA, Day TA (2009) Coping with defeat: acute glucocorticoid and forebrain responses to social defeat vary with defeat episode behaviour. Neuroscience 162:244-253. CrossRef Medline

Walker P, Carrive P (2003) Role of ventrolateral periaqueductal gray neurons in the behavioral and cardiovascular responses to contextual conditioned fear and poststress recovery. Neuroscience 116:897-912. CrossRef Medline

Yang SJ, Yu HY, Kang DY, Ma ZQ, Qu R, Fu Q, Ma SP (2014) Antidepressant-like effects of salidroside on olfactory bulbectomy-induced pro-inflammatory cytokine production and hyperactivity of HPA axis in rats. Pharmacol Biochem Behav 124:451-457. CrossRef Medline

Yizhar O, Fenno LE, Davidson TJ, Mogri M, Deisseroth K (2011) Optogenetics in neural systems. Neuron 71:9-34.

Zhang L, Hernández VS, Medina-Pizarro M, Valle-Leija P, Vega-González A, Morales T (2008) Maternal hyperthyroidism in rats impairs stress coping of adult offspring. J Neurosci Res 86:1306-1315. CrossRef Medline

Ziegler DR, Edwards MR, Ulrich-Lai YM, Herman JP, Cullinan WE (2012) Brainstem origins of glutamatergic innervation of the rat hypothalamic paraventricular nucleus. J Comp Neurol 520:2369-2394. CrossRef Medline 